4 norden 



\section{Driving forces behind the environmental pressure in Nordic countries - com- parative decomposition analyses}

An assessment of alternative methodological approaches

Annegrete Bruvoll

Taran Fæhn

TemaNord 2007:507 
Driving forces behind the environmental pressure in Nordic countries - comparative decomposition analyses

An assessment of alternative methodological approaches

TemaNord 2007:507

(C) Nordic Council of Ministers, Copenhagen 2006

ISBN 978-92-893-1442-8

Copies: Print-on-Demand0

This publication can be ordered on www.norden.org/order. Other Nordic publications are available at www.norden.org/publications

\section{Nordic Council of Ministers}

Store Strandstræde 18

DK-1255 Copenhagen K

Phone (+45) 33960200

Fax (+45) 33960202

www.norden.org

\author{
Nordic Council \\ Store Strandstræde 18 \\ DK-1255 Copenhagen K \\ Phone (+45) 33960400 \\ Fax (+45) 33111870
}

\section{Nordic Environmental Co-operation}

The Nordic Environmental Action Plan 2005-2008 forms the framework for the Nordic countries' environmental co-operation both within the Nordic region and in relation to the adjacent areas, the Arctic, the EU and other international forums. The programme aims for results that will consolidate the position of the Nordic region as the leader in the environmental field. One of the overall goals is to create a healthier living environment for the Nordic people.

\section{Nordic co-operation}

Nordic co-operation, one of the oldest and most wide-ranging regional partnerships in the world, involves Denmark, Finland, Iceland, Norway, Sweden, the Faroe Islands, Greenland and Åland. Cooperation reinforces the sense of Nordic community while respecting national differences and similarities, makes it possible to uphold Nordic interests in the world at large and promotes positive relations between neighbouring peoples.

Co-operation was formalised in 1952 when the Nordic Council was set up as a forum for parliamentarians and governments. The Helsinki Treaty of 1962 has formed the framework for Nordic partnership ever since. The Nordic Council of Ministers was set up in 1971 as the formal forum for co-operation between the governments of the Nordic countries and the political leadership of the autonomous areas, i.e. the Faroe Islands, Greenland and Åland. 


\section{Table of contents}

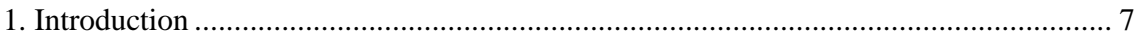

1.1 Background and purpose of the pre-study ……................................................. 7

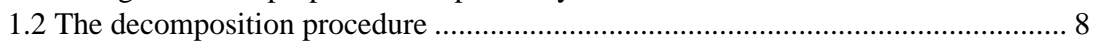

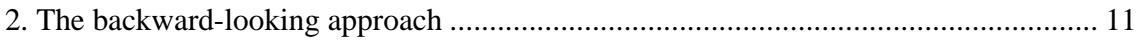

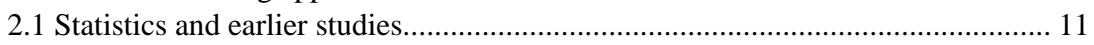

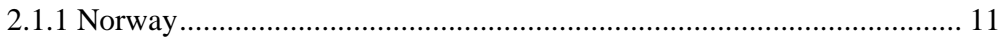

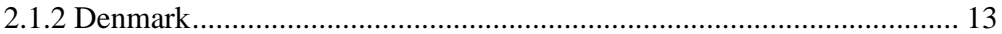

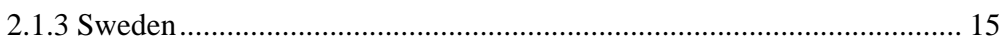

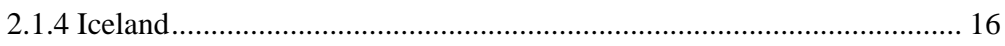

2.1.5 Comparisons of the available studies …................................................ 17

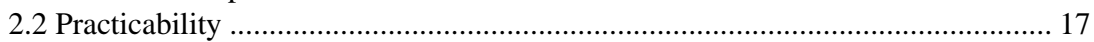

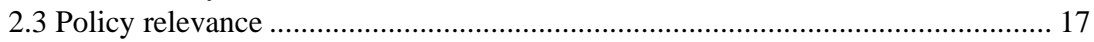

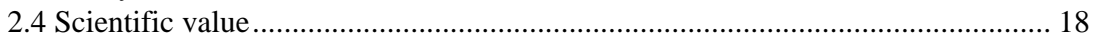

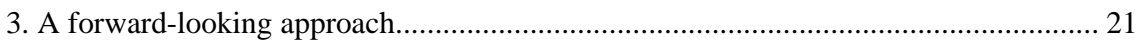

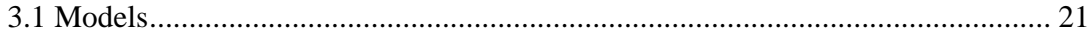

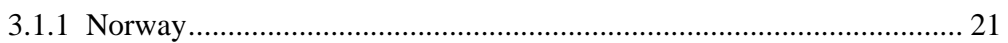

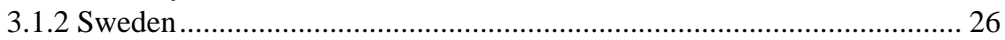

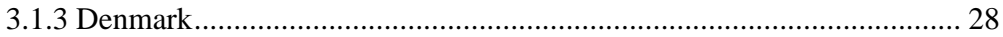

3.1.4 Iceland .............................................................................. 30

3.1.5 Compatibility and comparability of the Nordic models ......................... 33

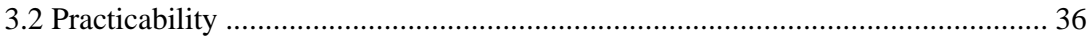

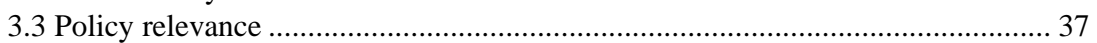

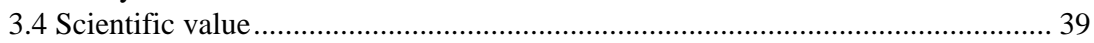

4. Conclusions and recommendations on the project design ........................................... 41

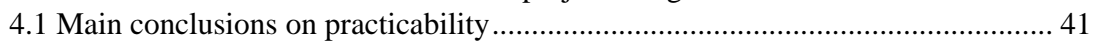

4.2 Main conclusions on policy relevance............................................................. 41

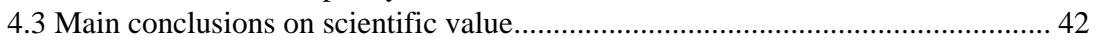

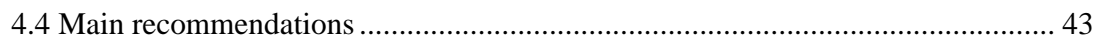

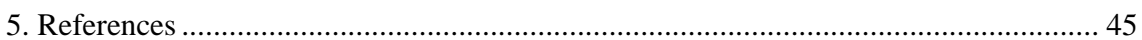





\section{Introduction}

\subsection{Background and purpose of the pre-study}

The Nordic Council of Ministers (NCM) considers initiating a project with the purpose to identify the driving forces behind the development of Nordic emissions to air. Two approaches are under consideration: a backward-looking and a forward-looking. The backward-looking approach aims to identify the reasons for the growth of emissions over the past decades. This analysis requires detailed statistical information on emissions from firms and households in (at least) two observation years covering the period of interest: preferably the most recent year available, and a historical year some 10-20 years before. The forward-looking approach would exploit a simulated data set. In addition to a year representing today, the remaining observation year(s) would be in the medium- or long-term future (20-50 years ahead). Simulation of data for the Nordic countries would be based on economic models.

This pre-study assesses the possibilities to conduct backward-looking and forward-looking decomposition analyses for the Nordic countries, Norway, Sweden, Denmark, and Iceland. We have evaluated the potentials of the two approaches in terms of their:

- practicability, i. e. the possibilities, restraints and costs of implementting the two methods. This involves an evaluation of the state of historical data (the backward-looking alternative) and the analytical tools, data, models and expertise (the forward-looking alternative) within each participating country, their quality and comparability. We also consider the need and methods for coordinating the country studies.

- policy-relevance, i. e. to what extent they enlarge the basis for conducting environmental policy and help to identify where to implement police measures efficiently.

- scientific value, i. e. to what extent they provide value added in terms of new empirical, theoretical or methodological information. The innovative value of a Nordic decomposition study is assessed in light of similar, already existing studies, in particular of Nordic countries.

Based on these evaluations we offer tentative conclusions on the best possible designs of the project. 


\subsection{The decomposition procedure}

Both for the backward-looking and the forward-looking analysis would be based on a method of full decomposition, as in Selden et al. (1999), Bruvoll and Medin (2003), Bruvoll, Fæhn and Strøm (2003) and Bruvoll and Larsen (2004). We aim to decompose the changes in emissions into 5 main elements: scale, composition, energy and intermediate intensity, energy mix and other technological changes. The emissions at the observation point $t$ can be factorised as follows:

$$
P_{t} \equiv \sum_{i} \sum_{j} \frac{P^{e}{ }_{i j t}}{E_{i j t}} \frac{E_{i j t}}{E_{j t}} \frac{E_{j t}}{Y_{j t}} \frac{Y_{j t}}{Y_{t}} Y_{t}+\sum_{j} \frac{P^{p}{ }_{j t}}{M_{j t}} \frac{M_{j t}}{Y_{j t}} \frac{Y_{j t}}{Y_{t}} Y_{t}
$$

$P$ : emissions, $E$ : energy use, $Y$ : production, $M$ : input of intermediates, $e$ : energy related, $p$ : process related

$j$ : sectors, $i$ : energy commodities,

$t$ : time or scenario $=0,1$

Two types of emission changes may be identified: changes in emissions over time, and, relevant to the forward-looking simulated data set, changes due to shifts in policy or other alternative assumptions. Hence, $t=0,1$ refer to time 0 and 1 or scenario 0 or 1 . The changes in emissions from $t$ $=0$ to $t=1$ can be decomposed as follows:

$$
\begin{aligned}
& P_{1}-P_{0}=P_{0}\left[\frac{Y_{1}}{Y_{0}}-1\right]+\sum_{j} P_{j 0}\left[\frac{Y_{j 1}}{Y_{j 0}}-\frac{Y_{1}}{Y_{0}}\right]+\sum_{j} P^{e}{ }_{j 0}\left[\frac{E_{j 1}}{E_{j 0}}-\frac{Y_{j 1}}{Y_{j 0}}\right]+ \\
& \sum_{j} \sum_{i} P^{e}{ }_{i j 0}\left[\frac{E_{i j 1}}{E_{i j 0}}-\frac{E_{j 1}}{E_{j 0}}\right]+\sum_{j} \sum_{i} P^{e}{ }_{i j 0}\left[\frac{P^{e}{ }_{i j 1}}{P^{e}}-\frac{E_{i j 0}}{E_{i j 0}}\right]+ \\
& \sum_{j} P^{p}{ }_{j 0}\left[\frac{M_{j 1}}{M_{j 0}}-\frac{Y_{j 1}}{Y_{j 0}}\right]+\sum_{j} \sum_{i} P^{p}{ }_{j 0}\left[\frac{P^{p}{ }_{j 1}}{P^{p}{ }_{j 0}}-\frac{M_{j 1}}{M_{j 0}}\right]
\end{aligned}
$$

i.e. the scale component, the composition component, the energy intensity component, the energy mix component, the other technique components for energy related emissions, the material intensity component and the other technique component for process related emissions. Table 1 shows the data, statistical or simulated, needed to perform this full decomposition analysis for the chosen t's and for each country. 
Table 1. Data needed for the performance of the full decomposition analysis.

\begin{tabular}{|c|c|c|c|c|c|}
\hline Production & & Sector $j=1$ & Sector $j=2$ & Sector $j=3 \ldots .$. & \\
\hline$Y_{j t}$ & & $Y_{j=1}$ & $Y_{j=2}$ & $Y_{j=3}$ & $\ldots$ \\
\hline \multicolumn{6}{|c|}{$\begin{array}{l}\text { Intemediate } \\
\text { inputs }\end{array}$} \\
\hline $\mathrm{M}_{\mathrm{jt}}$ & & $M_{j=1}$ & $M_{j=2}$ & $M_{j=3}$ & $\ldots$ \\
\hline \multicolumn{6}{|l|}{ Energy use } \\
\hline $\mathrm{E}_{\mathrm{ijt}}$ & $\begin{array}{l}\text { Energy type } i=1 \\
\text { Energy type } i=2 \\
\text { Energy type } i=3 \\
\ldots\end{array}$ & $\begin{array}{l}E_{i=1, j=1} \\
E_{i=2, j=1} \\
E_{i=3, j=1} \\
\ldots\end{array}$ & $\begin{array}{l}E_{i=1, j=2} \\
E_{i=2, j=2} \\
E_{i=3, j=2} \\
\ldots\end{array}$ & $\begin{array}{l}E_{i=1, j=3} \\
E_{i=2, j=3} \\
E_{i=3, j=3} \\
\ldots\end{array}$ & $\begin{array}{l}\cdots \\
\cdots\end{array}$ \\
\hline \multicolumn{6}{|l|}{ Pollution } \\
\hline $\mathrm{P}_{\mathrm{ijt}}$ & $\begin{array}{l}\text { Related to energy type } i=1 \\
\text { Related to energy type } i=2 \\
\text { Related to energy type } i=3\end{array}$ & $\begin{array}{l}P^{e}{ }_{i=1, j=1} \\
P^{i} e_{i=2, j=1} \\
P^{e} e_{i=3, j=1}\end{array}$ & $\begin{array}{l}P^{e}{ }_{i=1, j}=2 \\
P^{i} e_{i=2, j=2} \\
P^{e} e_{i=3, j=2}\end{array}$ & $\begin{array}{l}P_{i=1, j=3}^{e_{i}} \\
P_{i=2, j=3} \\
P^{e_{i=3, j}=3}\end{array}$ & $\ldots$ \\
\hline$P^{p}{ }_{j t}$ & Related to processes & $P^{p}{ }_{j=1}$ & $P_{j=2}^{p}$ & $P_{j=3}^{p}$ & $\cdots$ \\
\hline
\end{tabular}

The quality and detail of the analyses depend upon correspondence on disaggregation between the data sources. In order to perform consistent decompositions, all data must be disaggregated to the same sector classification. To perform the full decomposition as in (2), pollution must be disaggregated on process and energy related emissions, and the energy related emissions must be linked to disaggregated energy sources. In its most simple form, without disaggregated data on energy and process related emissions, the decomposition reduces to

$P_{t} \equiv \sum_{j} \frac{P_{j t}}{E_{j t}} \frac{E_{j t}}{Y_{j t}} \frac{Y_{j t}}{Y_{t}} Y_{t}$

(3)

$P_{1}-P_{0}=P_{0}\left[\frac{Y_{1}}{Y_{0}}-1\right]+\sum_{j} P_{j 0}\left[\frac{Y_{j 1}}{Y_{j 0}}-\frac{Y_{1}}{Y_{0}}\right]+\sum_{j} P_{j 0}\left[\frac{E_{j 1}}{E_{j 0}}-\frac{Y_{j 1}}{Y_{j 0}}\right]+$
$\sum_{j} P_{j 0}\left[\frac{P_{j 1}}{P_{j 0}}-\frac{E_{j 1}}{E_{j 0}}\right]$

i.e. the scale component, the composition component, the energy intensity component, and the other technique component. This simple form is most relevant for typically non-process related emissions, such as $\mathrm{CO}_{2}$. 



\section{The backward-looking approach}

\subsection{Statistics and earlier studies}

\subsubsection{Norway}

Available data

The emissions and energy accounts in Statistics Norway offer data on emissions and energy use on a detailed aggregation level of 125 sectors for the years 1980, 1987, 1989-2004. The calculation of the emissions is closely and consistently related to energy use at the same aggregation level. The sector aggregation is based on the international NACE classification. The National accounts offer data on production and material input on levels that are also based on NACE, but the aggregation is not identical. In order to perform the decomposition procedure, adjustment between the databases are needed.

Ensuring similar aggregation levels for all data is a relatively comprehensive task. An earlier decomposition study by Bruvoll and Medin (2003) uses an aggregation level of 8 sectors. Only energy data exists for this database, hence all the other data were aggregated to perform the decomposition analysis. The databases are documented in Bruvoll, Flugsrud and Medin (2000). The aggregation problems are still valid for more recent updates of the existing databases.

\section{Earlier studies}

The most extensive Norwegian decomposition analysis is the study by Bruvoll and Medin (2003). This study comprises changes in 10 pollutants $\left(\mathrm{CO}_{2}, \mathrm{SO}_{2}, \mathrm{NO}_{\mathrm{x}}, \mathrm{CO}, \mathrm{PM}, \mathrm{VOC}, \mathrm{CH}_{2}, \mathrm{~N}_{2} \mathrm{O}\right.$ and $\left.\mathrm{NH}_{3}\right)$. The analysed data set corresponds to all the variables in Table 1, and consists of 8 sectors and 18 energy types for the years 1980, 1987 and 1989-1996. The main conclusions from this study are that reduced energy intensity and other technological changes, i.e. abatement technologies, have been the main driving forces counteracting economic growth, see figures. Further, substitution of cleaner for polluting energy types and other technological progressions have reduced the growth in emissions. The composition effect was less important to the development in energy related emissions. However, the increased significance of Norwegian oil production contributed to increase the otherwise emission reducing structural changes. 

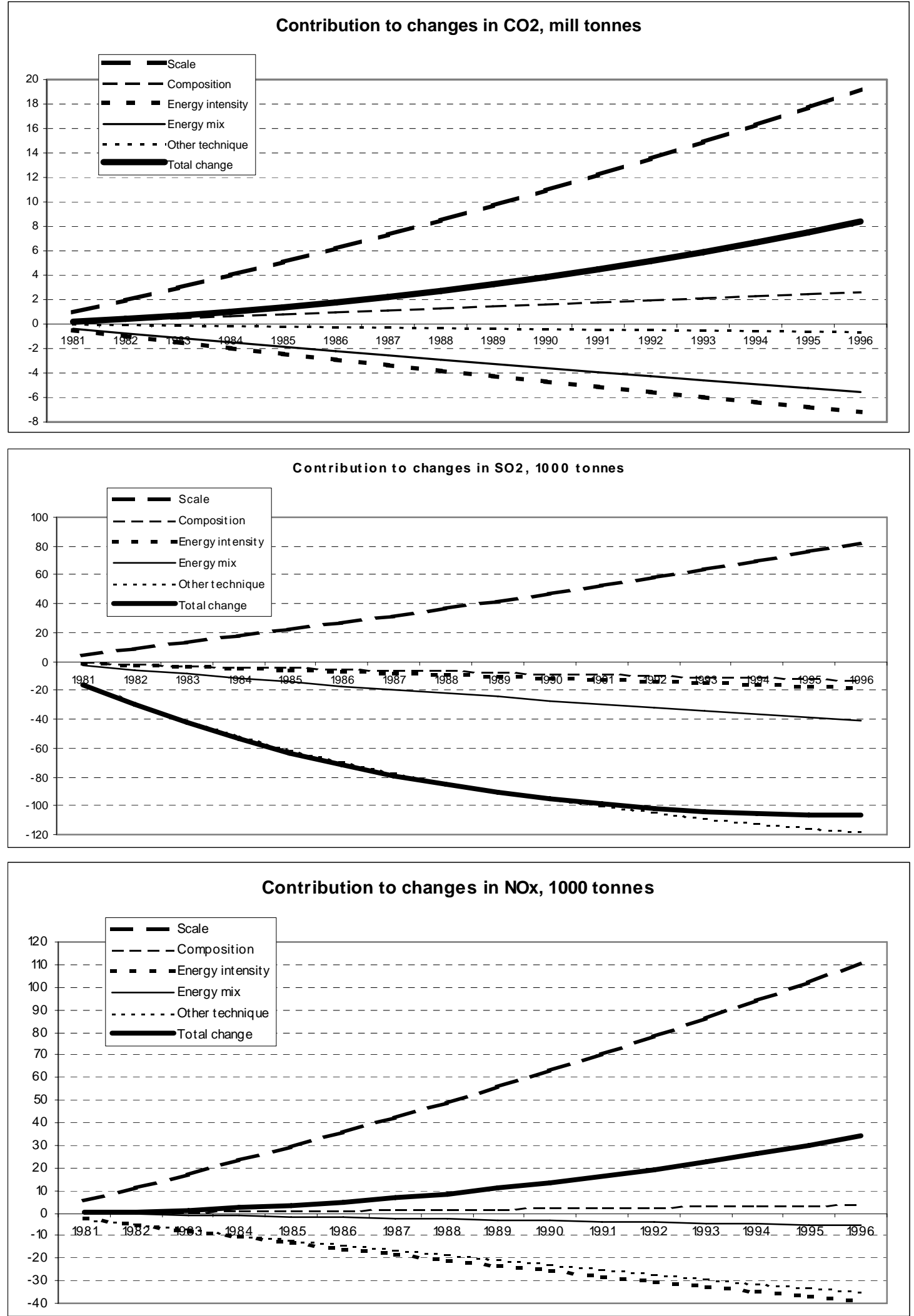
Sensitivity analyses in Bruvoll and Medin show that the main findings are stable with respect to the time period investigated, but somewhat more unstable when comes to sector aggregation. Another sensitivity analysis in Bruvoll and Medin based on the data set of 125 sectors, comparing the changes from 1991 to 1996, shows that structural changes were more important for process related emissions.

\subsubsection{Denmark}

Available data

The NAMEA database (http://www.dst.dk/) contains the data needed for decomposition of Danish emission changes. The database contains data on the emissions of $\mathrm{CO}_{2}, \mathrm{SO}_{2}, \mathrm{NO}_{\mathrm{x}}, \mathrm{CO}, \mathrm{NH}_{3}, \mathrm{~N}_{2} \mathrm{O}, \mathrm{CH}_{4}$ and NMVOC at a 2-digit NACE level. The main source for the energy related emissions is Statistics Denmark's energy matrices. At the most detailed level, the energy matrices consist of 40 types of energy and 130 industries. Emissions can be disaggregated on process and energy related emissions, and linked to each energy type generating the emissions. The energy matrices, the emission accounts and the national accounts are consistent. Hence, it is possible to relate emissions, energy, intermediate inputs and production in a decomposition analysis according to Table 1 . The database further includes transboundary emissions in and out of Denmark, which opens for estimations of emission leakages.

\section{Earlier studies}

The NAMEA database has already been used in a decomposition analysis of changes in air emissions in Denmark from 1980 to 2001 (Jensen and Olsen 2003). Jensen and Olsen decompose changes in emissions to air into mainly into the same factors as Bruvoll and Medin (2003). Another, earlier study, decomposes nitrogen changes in different sectors into changes in emissions factors, input mix, demand mix, and total demand over the period 1966-1988 (Wier and Hasler 1999). This study does not reveal sector composition effects.

The results from Jensen and Olsen show that the emission reducing factors vary a lot between types of emissions, see the following figures. The approximate correspondence between the symbols in the figures and the components in Bruvoll and Medin are as follows:

- Emmcoef: other technological changes

- Enmix: energy mix

- Eint: energy intensity

- Input: composition effect

- FDlevel: scale effect (the effect of economic growth) and

- FDstruct: captures changes in consumer preferences 
Decomposition of $\mathrm{CO}_{2}$ emissions from all industries $1980-2001$

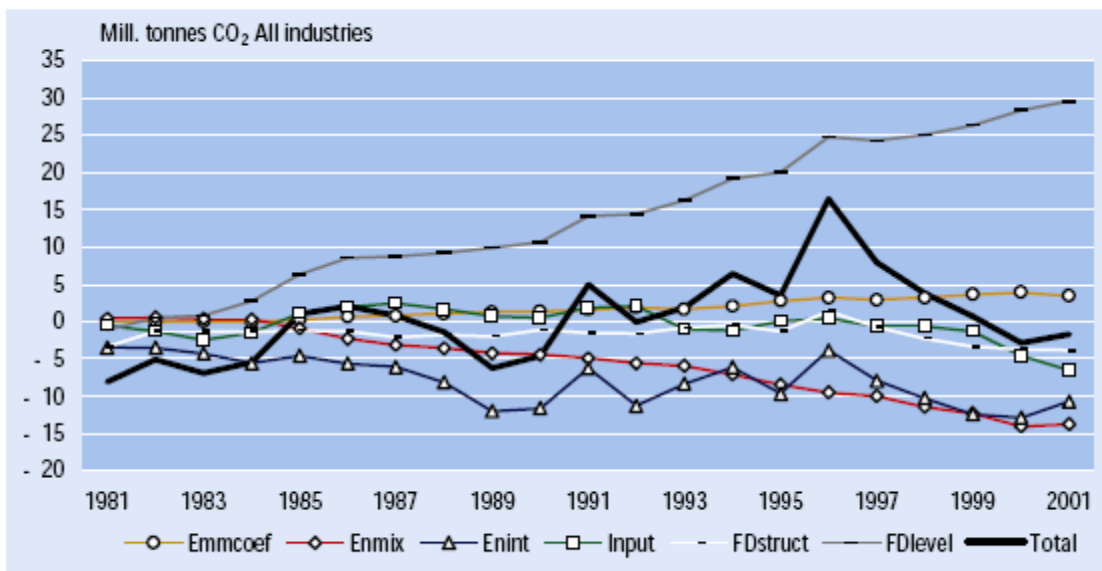

Source: Jensen and Olsen (2003)

\section{Decomposition of $\mathrm{SO}_{2}$ emissions from all industries 1980 - 2001}

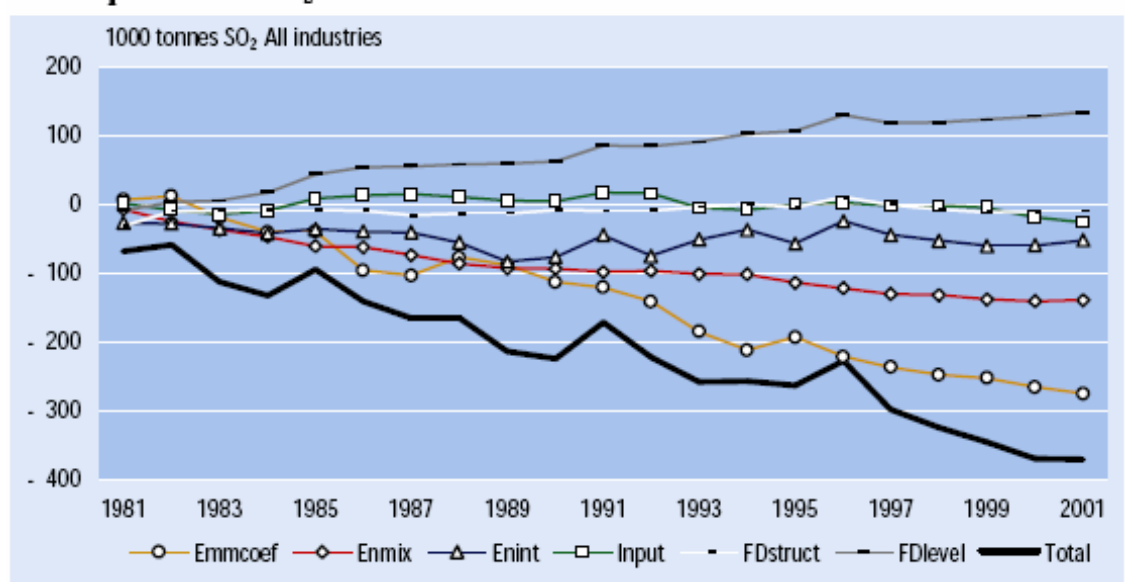

Source: Jensen and Olsen (2003)

\section{Decomposition of $\mathrm{NO}_{\mathrm{x}}$ emissions from all industries $1980-2001$}

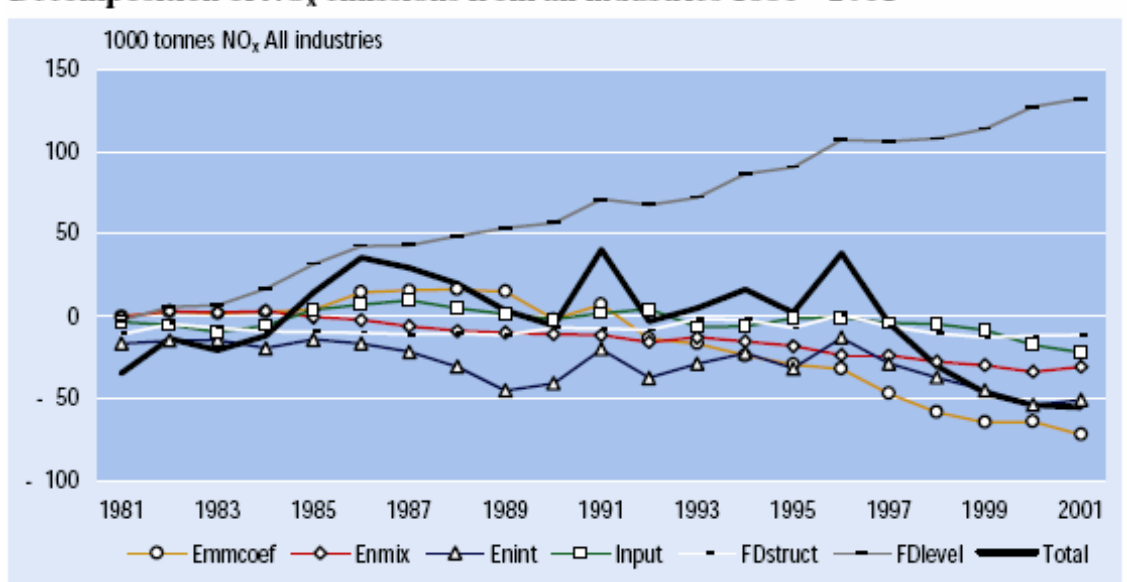

Source: Jensen and Olsen (2003) 
Decomposition of $\mathrm{SO}_{2}$ emissions from households 1980 - 2001

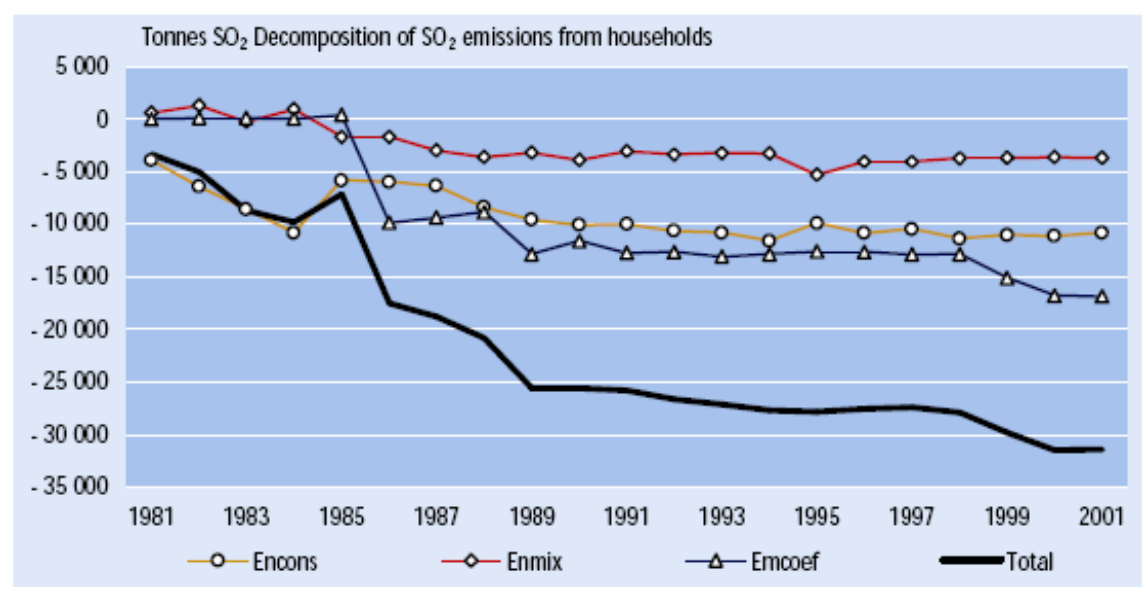

Source: Jensen and Olsen (2003)

Decomposition of $\mathrm{NO}_{\mathrm{x}}$ emissions from households 1980 - 2001

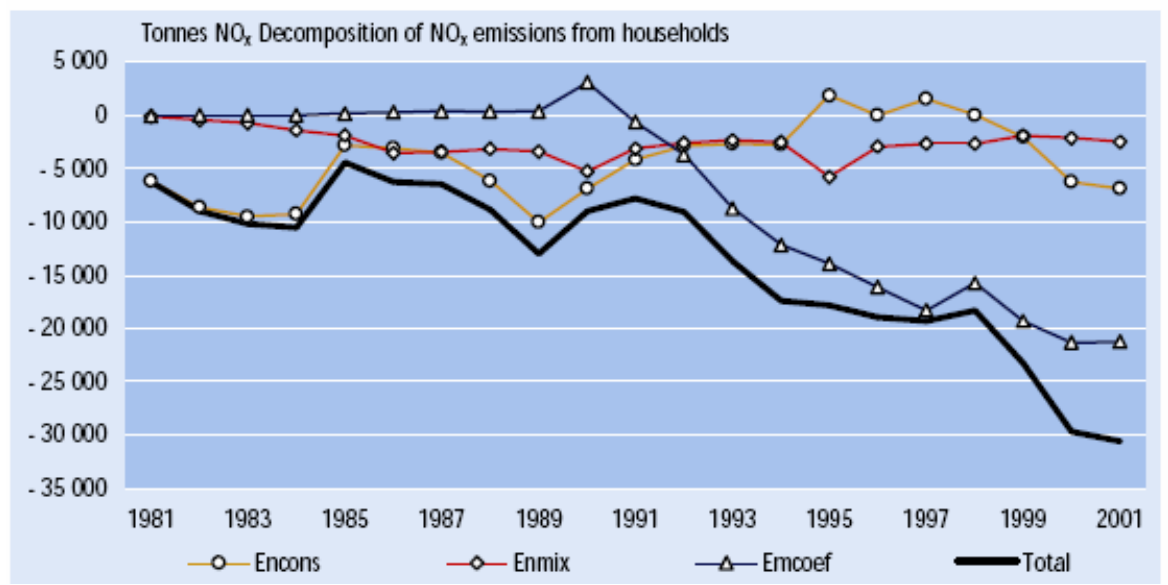

Source: Jensen and Olsen (2003)

\subsubsection{Sweden}

Available data

Statistics Sweden has time series over the period from 1993 to 2003 (National Accounts and Environmental Accounts) at a 2-digit NACE level, including 55 sectors, for emissions, energy use and production (http://www.mirdata.scb.se/MDInfo.aspx). Energy use is disaggregated on 35 energy sources. Emission data is available for $\mathrm{CO}_{2}, \mathrm{SO}_{2}, \mathrm{NO}_{\mathrm{x}}, \mathrm{CO}$, $\mathrm{NH}_{3}, \mathrm{~N}_{2} \mathrm{O}, \mathrm{CH}_{4}, \mathrm{NMVOC}, \mathrm{PM}_{10}, \mathrm{PM}_{25}$ and TSP. The emissions are disaggregated on stationary, mobile and process emissions. 
Earlier studies

Based on Swedish Environmental Accounts, Wadeskog and Palm (2003) conduced a structural decomposition analysis of $\mathrm{CO}_{2}$ for the 1993-1999 period. The main results are presented in the following figure. The composition of sectors (Structure FD) had a dampening effect on $\mathrm{CO}_{2}$ emissions, while the emission intensity first contributed to increase, then to decrease emissions.

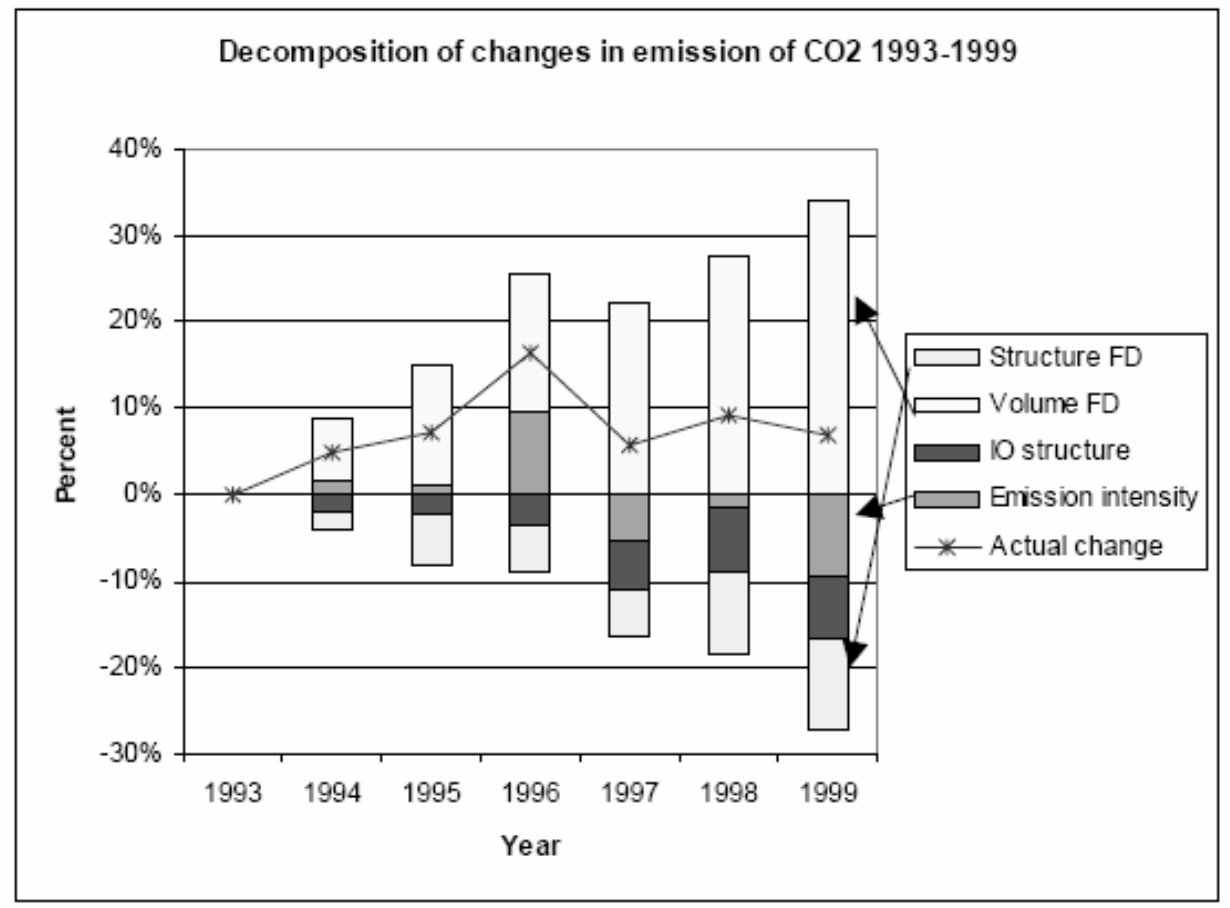

Source: Wadeskog and Palm (2003)

\subsubsection{Iceland}

The emission registry reported by The Environment and Food Agency of Iceland to the UN treaty on climate change (UNFCCC) contains energy and energy related emission data for the Kyoto gases for the years 1990 to2003 http://ust.is/Mengunarvarnir/Hnattraenmengun/Grodurhusaahrifin /Itarefni/), and 2004 is in preparation. For energy related emissions, sectors are disaggregated to 13, plus 5 transport sectors, and energy is disaggregated to 5 fuels. Emissions are further disaggregated and directly related to fuel types. Process related emissions are disaggregated on 4 industrial sectors, in addition to agriculture, land use and forestry, and waste.

Statistics Iceland (www.statice.is) offers data for $\mathrm{CO}_{2}, \mathrm{NO}_{\mathrm{x}}, \mathrm{SO}_{2}$ and NMVOC disaggregated on 9 sectors for the years 1990-2004. Production and intermediate consumption is available at a rather detailed level, that can be a basis for aggregation to the emission sector level. In order to perform a detailed decomposition analysis, the energy- and emission data 
in the emission registry needs to be combined with the economic data from Statistic Iceland's databases, and adjustments are needed to approach to a consistent aggregation level.

\subsubsection{Comparisons of the available studies}

The decompositions of emissions in Denmark and Norway show clear similarities. The emission increasing force is the scale effect, that is counteracted by different forms of technological progress (changes in energy mixture, energy intensity, and reduced emission coefficients).

Total CO2 emissions increase inn both countries, and the main reducing effects are energy intensity and energy mix (note that in the figures, the Danish decompositions end in 2001, while the Norwegian end in 1996). Structural changes and emission coefficients have little impact. The similarities for the decomposed changes in SO2 emissions are obvious. In both countries, the emissions are reduced, and the main cause is "other technological changes", i.e. reduced emissions per unit of energy use. Changes in the energy mix is the second most important factor in both countries, then energy intensity and, finally, structural changes has some emission reducing effect. We find the same similarities for the emissions of NOx for the period 1980 to 1996.

The Swedish study covers fewer years. Notably, the energy intensity component contributes to increase CO2 emissions in 1996. The reason may be the high electricity prices that year, that induced a substitution over to fossil fuels. The same tendency is found in the Danish data, as the energy intensity effect was less negative in 1996. Otherwise, the Swedish decomposition confirms the findings above.

\subsection{Practicability}

The conclusion from this mapping of data is that data are available at a fairly detailed and consistent level for Denmark, Norway and Sweden. For Iceland and Norway, adjustments between sectors of the data series are needed. The sector classification varies between the countries. This complicates the comparison of the results.

The most practical organisation of a backward-looking approach seems to be as individual subprojects for each country, conducted by or in cooperation with the respective countries' statistical institutions.

\subsection{Policy relevance}

It is not possible to isolate the impact of policy - or other causal relationships - in a decomposition of historical emission changes between two 
points in time. This would require a study of different scenarios and would require use of counterfactual methods in addition to the decomposition method. Combined with knowledge about the timing and strength of policy reforms, decompositions of historical data may nevertheless help to point out potential interesting policy effects. How policy variables have affected emissions could be further revealed in econometric analyses where the role of energy prices relative to other input prices, technological change and other variables influencing the intensities, are controlled for. In some cases, pretty clear implications may be drawn. As an example, the other technique component reduces $\mathrm{SO}_{2}$ significantly, while it has hardly any effect on $\mathrm{CO}_{2}$ emissions. A plausible reason is that $\mathrm{CO}_{2}$ cannot be abated, while the sulphur taxes have effectively reduced the emission coefficients for $\mathrm{SO}_{2}$.

Historical decomposition can however reveal some trends in driving forces that indicates targets for environmental policy. To benefit from a coordinated Nordic context, the most relevant historical time period needs to be specified. Still, it is not given that the historical trends will be prolonged into the future. In a study of Norway, Bruvoll and Fæhn (2006) compare the results of a forward-looking and a backward-looking approach. The conclusion is that results are difficult to generalise and, in particular, that there are many important differences between past and future driving forces to emission growth. Further, the vast literature on environmental Kuznets curves and decoupling (see e.g. the survey by Dinda, 2004) shows the extensive sensitivity of environmental indicators to economic income growth.

Given this uncertainty, the challenge of using backward-looking analyses as a basis for future policymaking is to consistently adjust the historical findings to the available knowledge and realistic expectations about future economic growth, technological and structural changes, and external policy restraints.

\subsection{Scientific value}

For Norway and Denmark there already exist rather detailed decomposition analyses of historical data, and the previous studies show relatively consistent trends that are plausible given the historical price variations in energy prices, environmental policy and economic development. Thus, we consider the possibilities for finding new research hypotheses and results within further decomposition studies as limited.

In addition to the decomposition method shown in 1.2, several other methods for decomposition exist. The innovation of new methodologies is however not part of this project.

If the backward-looking perspective will be chosen in a coordinated study of the Nordic countries, process related emissions could be added 
for the Danish case. For Sweden, other emissions than $\mathrm{CO}_{2}$ could be investigated. However, before doing so, the aim of the project and the hypotheses for possible new findings should be clarified. 



\section{A forward-looking approach}

\subsection{Models}

For making projections of the economic driving forces explaining emissions in the future, economic models are appropriate tools. Economywide simulations will be better than combining information from several partial market models. The most preferable in a Nordic study would have been a general model that incorporates all the Nordic countries: However, economy-wide (general), detailed models for the Nordic countries as an entity are not yet developed. The practical solution is thus to coordinate simulations on general models for each Nordic country.

Which economy-wide models that are most suitable for the forwardlooking analyses depend on the time horizon. Macro-econometric models are designed for short-run forecasts (usually from 1 quarter to 2-3 years ahead) and emphasise short-run dynamics in time series data. For longerrun projections, the most commonly used tools are computable general equilibrium (CGE) models, solving for states where the economy is in balance, in the sense that all adjustments and inertia in the markets are faded out. These equilibrium states, where desired demand equals desired supply, are obtained by market price adjustments. In practice, most empirical large-scale models include elements of both these traditions; they have features that are partly motivated by econometric evidence, partly motivated by economic equilibrium theory. We suggest a horizon that stretches for decades; say 10-40 years. For that purpose CGE models will in general be the most appropriate.

Running and analysing large-scale economic models requires modelspecific competence and experience. In a coordination of several models, participation of researchers associated to the various national model institutions is necessary. This pre-study includes a mapping among Nordic model groups of their interest to participate and the relevance of their models. In addition, we rely on information gathered in the former decoupling project lead by Jon Thor Sturluson, and we refer to his report Sturluson (2005).

\subsubsection{Norway}

Model and expertise: The Norwegian model we plan to use is the MSG6 model of Statistics Norway. This model is used for a similar study in Bruvoll, Fæhn and Strøm (2003) and Bruvoll and Larsen (2004). The model is widely used in projections and policy analyses, both by Statistics Norway and by the government. Heide et al. (2004) gives a documen- 
tation of the model, while Strøm (2000) describes the emission module in detail. For applications to environmental policy analyses, see Bruvoll and Fæhn (2006), Bruvoll and Fæhn (2004), Bruvoll and Larsen (2004), Bruvoll, Fæhn and Strøm (2003), Bye and Nyborg (2003), Fæhn and Holmøy (2003), Bye (2002), Strøm (2001), and Bye (2000).

Empirical and theoretical features: MSG6 is a CGE model suitable for long-run projections. The usual time span in studies on the MSG6 model is 10 to 60 years. It is spinned down to Norwegian evidence by means of both calibration and estimation methods. The Norwegian National Account, supported by the Energy Statistics and the Emission Accounts, all delivered by Statistics Norway, are the main empirical sources of goods, factor and emission flows. Several econometric studies form the basis for the estimates used in the model. The government frequently uses the model in combination with macro-econometric models and put much effort into trying to track short-run forecasts. They apply a static version of the model, in the sense that they treat agents as behaving on basis of information from past and current periods. The most commonly used versions for research purposes, both for projections and for analyses of policy shifts, are intertemporal and treat both consumers and producers as forward-looking with perfect expectations about future variables. An impact of using the dynamic versions of the model is that the current account and trade balance adjust endogenously to the decisions of the agents' preferred time profile of consumption. The current account is only restricted over the long term by an intertemporal budget constraint that prevents the aggregate debt (or wealth) of the country to explode.

The firms have some market power in the domestic market, a feature supported by empirical analyses of the Norwegian economy. Producer behaviour at home is therefore characterised by monopolistic competition. On the world markets, however, prices are fixed, suggesting that producers are confronted with free competition and act as price takers in the export markets. Technological change is exogenous, with one exception: Electricity can be generated by two different technologies, hydropower, which is the current technology, and gas power, which will be faced in if profitability allows. In all industries, production techniques continuously change in accordance with relative factor price changes and substitutability among factors, which is given by the substitution parameters set in every level of the nested constant - elasticity - of - substitution (CES) input structure; see Figure 1. It can be interpreted as if the firm first chooses its allocation between variable inputs and structures at the top level of the tree, according to their relative prices and their (constant) degree of substitutability in production. Having chosen these relative levels, it goes on by choosing in the next level between commodity inputs and the composite of the remaining inputs (called modified value added), and so on. The price of a composite is an index of the prices of the goods 
comprising the composite. For capital input, the user costs are the relevant prices.

Consumers decide on their consumption profile according to an intertemporal elasticity set to 0.3, which is consistent with Steigum (1993). Leisure, and thereby labour supply, is part of the utility function and is endogenously determined by the consumers' optimisation, along with the decisions on consumption of each good. The model can easily be closed in a manner that fixes total labour supply exogenously.

The model is consistent with the small, open economy paradigm, where all agents have access to world goods and capital markets at exogenously determined prices and interest rates. An implication is that export prices do not adjust to domestic cost changes. This modelling avoids that there will be so-called terms of trade gains for the country of raising their costs of export through e.g. a relative increase in production costs of export-oriented sectors or an increase in export levies. Coexistence of both export and home market deliveries when domestic and foreign prices differ is ensured by assuming there are costs of diverting deliveries between the markets, through a constant-elasticity-to-transformation function. Quite analogously, coexistence of both imported and domestically produced varieties of a good is ensured by an assumption of heterogeneity in demand between varieties of, respectively, domestic and foreign origin (the Armington assumption).

Suitability for environmental decomposition analyses: MSG6 is highly disaggregated. It consists of 32 private production sectors, 7 government sectors and 60 consumption goods. Production technology is described with price-flexible production functions where labour, three types of physical capital, four types of energy, and material inputs from other sectors are the inputs. Special attention is given to transport services, due to their importance for emissions and in environmental policy. The structure of the production is shown in Figure 1. Consumer activities are also substitutable and highly disaggregated. In addition, they have different income elasticities. ${ }^{1}$ The structure of the nested CES utility function is shown in Figure 2.

\footnotetext{
${ }^{1}$ This is usually not a feature of CES utility technologies, where income elasticities are equal to 1 for each good. The Norwegian CES functions are however origo-adjusted, which ensures that income elasticities can differ from 1; see Aassness and Holtmark (1995).
} 


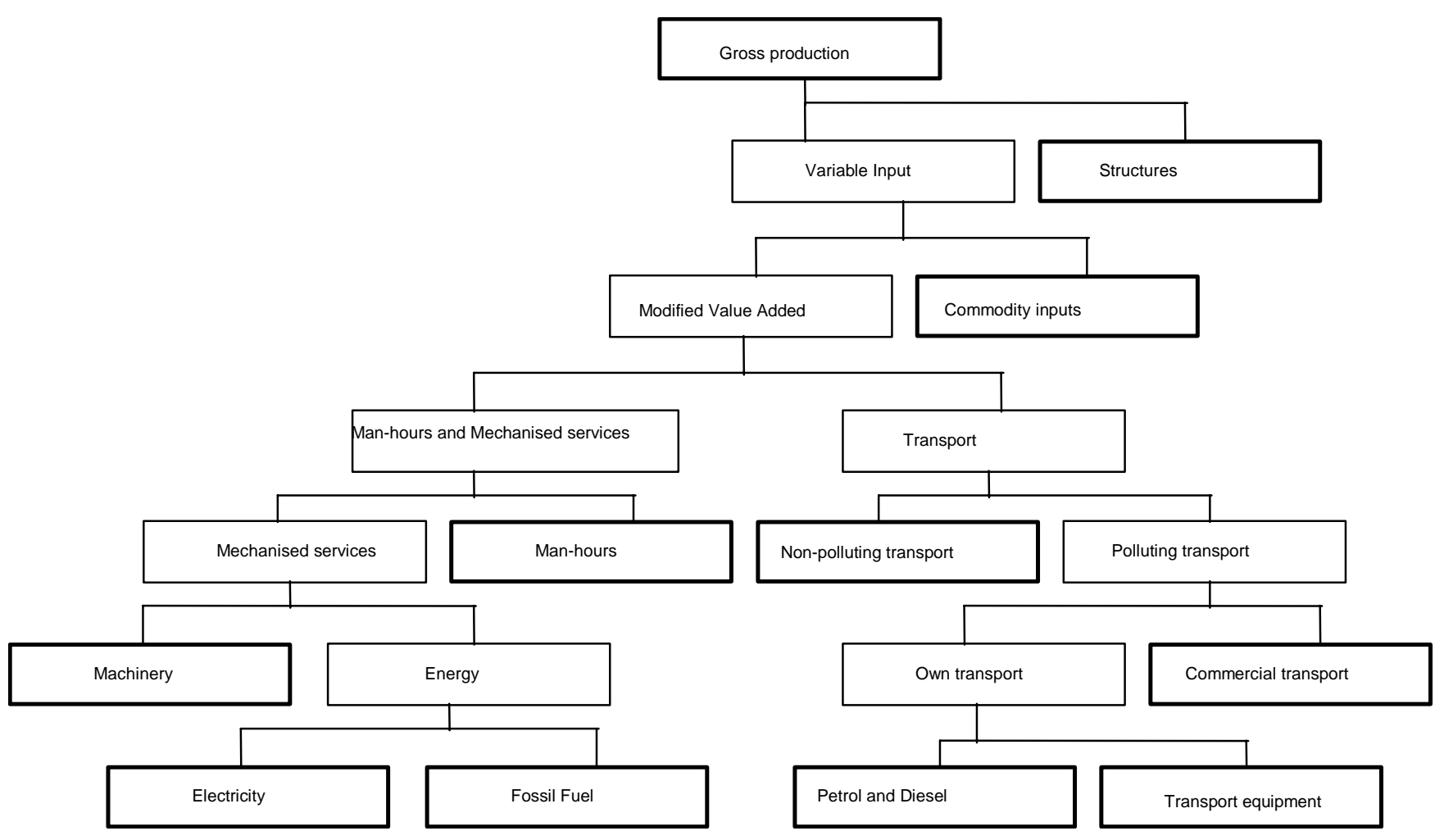

Figure 1: The structure of production in MSG-6

Source: Heide et al. (2004) 


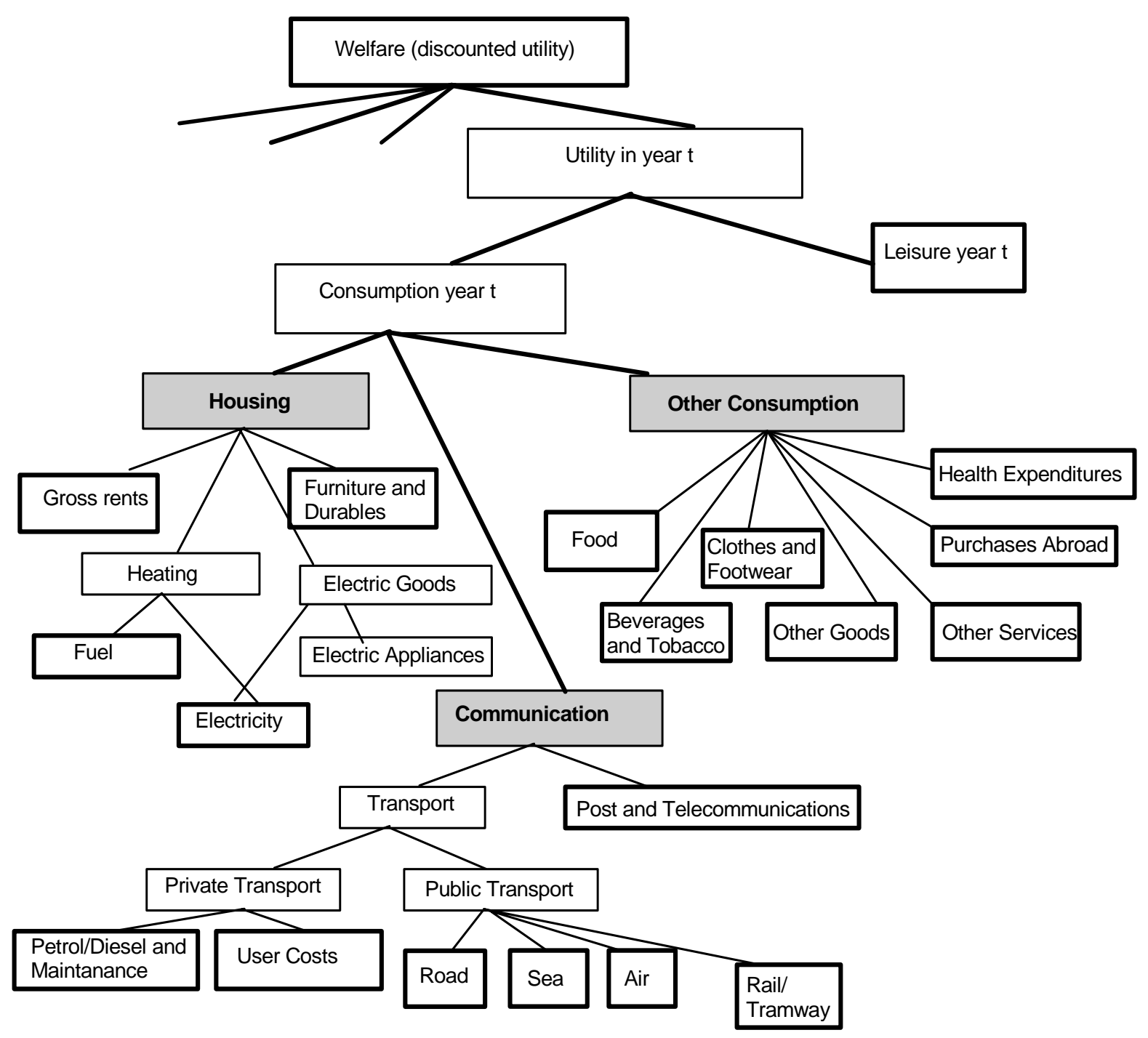

Figure 2: The structure of households' utility function in MSG-6

Source: Wold (1998)

MSG6 includes 12 different emission compounds, including the 6 Kyoto gases, along with Sulphur Dioxide $\left(\mathrm{SO}_{2}\right)$, Ammonia $\left(\mathrm{NH}_{3}\right)$, Nitrogen Oxides $\left(\mathrm{NO}_{\mathrm{x}}\right)$, Carbon Monoxide (CO), Non-Methane Volatile Organic Compounds (NMVOCs), and Suspended Particulates ( $\mathrm{PM}_{2,5}$ and $\mathrm{PM}_{10}$ ). The emissions are linked to the detailed economic activities emitting, like input of materials, energy inputs, production processes, consumption activities and landfills. In current versions, policy variables are linked to emissions of the 6 climate gases. The detailed level of the model, and the way emissions and policy instruments are linked to each activity, imply that the model is highly suited for decomposing emissions. 


\subsubsection{Sweden}

Model and expertise: For the Swedish part of the planned analysis, the EMEC (Environmental Medium-term EConomic) model will be used. It is developed at The National Institute for Economic Research (Konjunkturinstitutet, KI). Our contact persons are Eva Samakovlis, who leads the Unit of Environmental Economics Research, and Göran Östblom, who is the creator of EMEC. The model has been extensively used by the research group in governmental committees (SOU 2005:10, SOU 2003:60, SOU 2001:2, SOU 2000:45, SOU 2000:23) in long term surveys (SOU 2004:19, SOU 2000:7) and in several research projects (Östblom and Samakovlis 2004, Nilsson 2004, Östblom 2003, Nilsson and Huhtala 2000). Detailed model descriptions are presented in Östblom (1999) and Östblom and Berg (2006).

Empirical and theoretical features: Like the Norwegian model, EMEC is a CGE model, with perfectly rational agents. It is a static model solved for a future point of time and meant for medium-term analyses of economic and environmental issues. It is based on empirical data both with respect to the input-output flows, which are based on the Swedish National Accounts, with respect to the emission data, which are based on the physical environmental accounts of Statistics Sweden, and with respect to parameter choices, which are based on available econometric sources. All production sectors are characterised by perfect competition and constant returns to scale. Their inputs are nested in a CES tree of substitutable inputs (see Figure 3A below), quite similar to the Norwegian model. There are two types of labour (skilled and unskilled), five different energy sources (coal, natural gas, heating oils, bio-fuels, electricity, and district heating) and seven transport modes. Technological change is exogenous. Consumers have a nested CES utility function (see Figure 3B below) and decide on their consumption of goods and services, according to estimated substitution elasticities and relative prices. There are three types of work trips (bus, car and train), five types of leisure trips (bus, sea, car train and air) and five different energy sources (coal, natural gas, heating oils, bio-fuels, electricity, and district heating). The labour supply, the current account and the trade balance are exogenous.

Also in this model import prices and the interest rate are determined in the world markets. However, foreign demand for export products is downward-sloping, implying that export prices respond to Swedish costs. To avoid unrealistically strong terms-of-trade effects, the elasticities are set at rather high levels.

Suitability for environmental decomposition analyses: The industrial structure is flexible with respect to level of aggregation, with input-output data for 45 industries as a database. The current model distinguishes between 26 business sectors and one general government sector. Firms and households demand a mix of 33 goods and services as manufacturing inputs, for investment and for household consumption. Emissions of the 
Kyoto greenhouse-gases Carbon Dioxide $\left(\mathrm{CO}_{2}\right)$, Methane $\left(\mathrm{CH}_{4}\right)$, and Nitrous Oxide $\left(\mathrm{N}_{2} \mathrm{O}\right)$, emissions of the gases Sulphur Dioxide $\left(\mathrm{SO}_{2}\right)$, Nitrogen Oxides $\left(\mathrm{NO}_{\mathrm{x}}\right)$, Carbon Monoxide (CO) and Suspended Particulates $\left(\mathrm{PM}_{2,5}\right.$ and $\left.\mathrm{PM}_{10}\right)$ are incorporated by linking them to firms' use of materials and fuels and to households' fuel consumption. Energy and environmental taxes are imposed on the use of energy by households and firms. The Swedish model is well fit for a decomposition analysis.

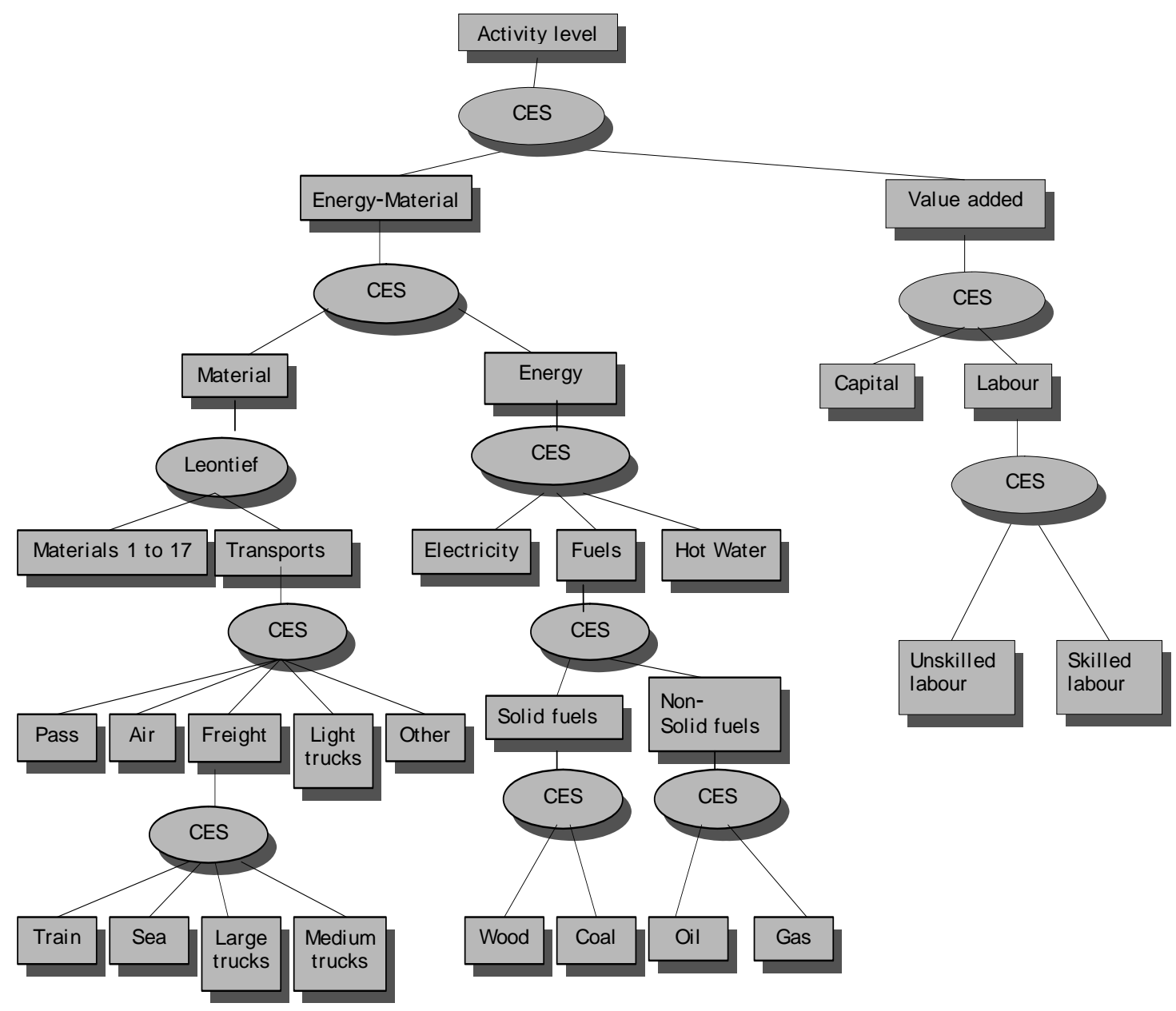

Figure 3 The input-activity specification in EMEC

Source: Östblom and Berg (2006) 


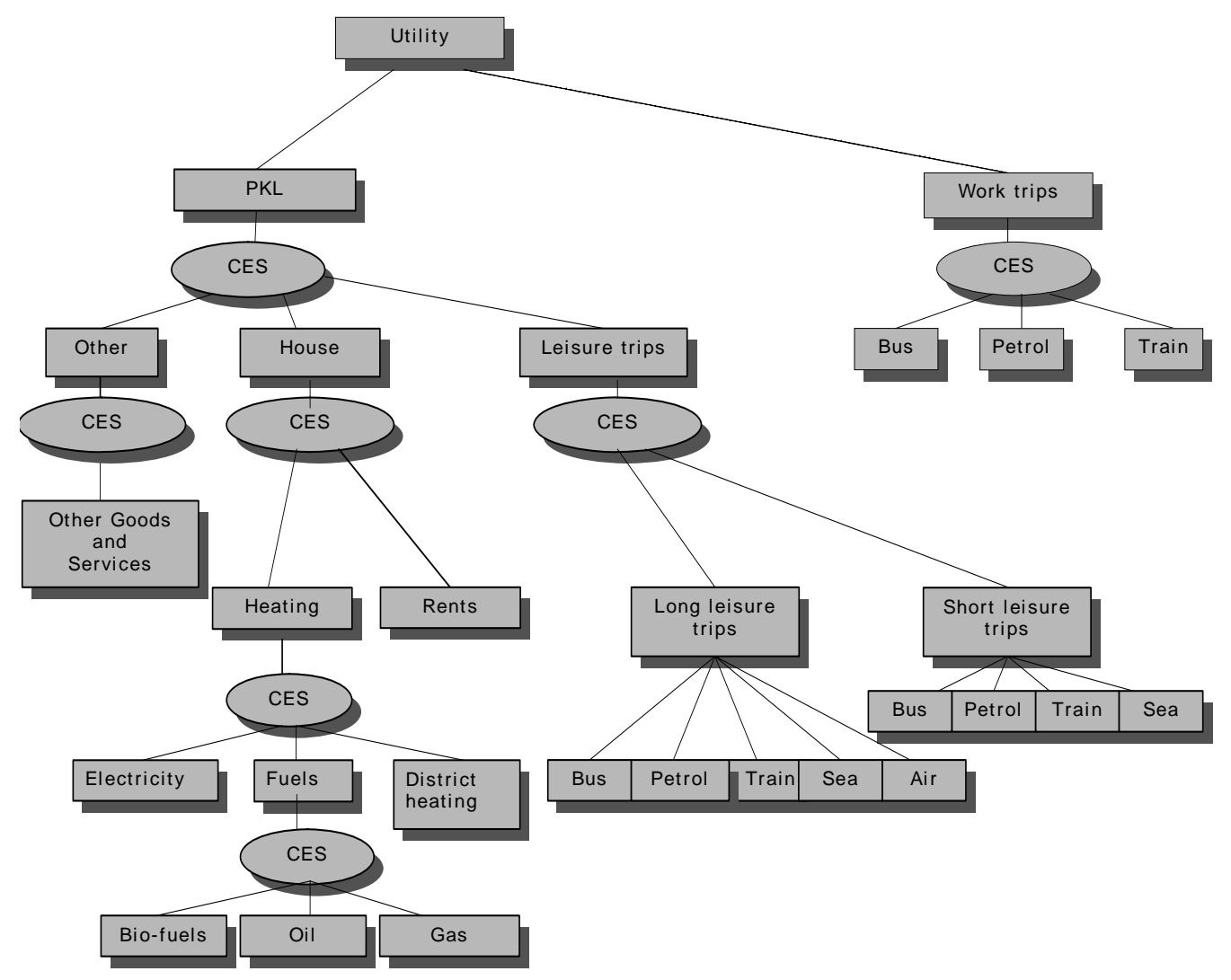

Figure 4 Consumer utility function.

Source: Östblom and Berg (2006)

\subsubsection{Denmark}

Model and expertise: The analysis of the Danish economy will be performed by using the ADAM model of Statistics Denmark, extended with the energy and emission satellite EMMA, developed by Statistics Denmark, National Environmental Research Institute of Denmark, and Risö National Laboratories. Them model is widely used for various forecasts and policy analyses by several institutions, including the Danish government, political parties and organisations. Our collaborators will be the ADAM group of Statistics Denmark, which has highly acknowledged competence on maintenance, development and application of the model. Our contact is head of the research group, Jes Asger Olsen. The ADAM and EMMA models are documented in Statistics Denmark (1996). Andersen et al. (1997) gives a more thorough documentation of EMMA.

Empirical and theoretical features: The ADAM model is, contrary to the other chosen models, a macro-econometric model. As it is frequently used for shorter-term forecasts for the next 1 to 5 years, it is to a higher degree than CGE models designed to track historically observed shortterm economic relationships. The model is also used for 10-20 years' 
projections, and by letting the model adjust fully to changes, it reaches a steady state for the economy, where the economic mechanisms rely more on economic equilibrium theory. A main difference from most CGE models is that it includes modelling of unemployment, while CGE models tend to assume that wages always adjust to ensure equilibrium in the labour market.

The consumers are not forward-looking, but besides the current household income, the consumption behaviour is dependent on household wealth. This formulation can be interpreted to reflect a consumptionsmoothing behaviour, like in the dynamic CGE models (Pedersen and Rasmussen, 2000).

The short-run bias of the ADAM model implies that trade elasticities are smaller in ADAM than in the CGE models. This, in combination with less flexible domestic wages and prices, implies that competitiveness and market shares of domestic firms are less sensitive to domestic changes. Domestic interest rates are determined by external conditions. The trade balance is endogenously determined. The development of the current account is not necessarily in accordance with intertemporal constraints on discounted values of net imports that prevent an continuously rising debt (or wealth). This deviates from the features of intertemporal CGE models.

Suitability for environmental decomposition analyses: The ADAM model consists of 19 industries. The input-output structure of ADAM is fairly aggregate, distinguishing between one composite each of labour, capital, energy and materials. But EMMA splits the aggregate energy good further into 7 different energy types, and also disaggregates transportation into more categories. EMMA models demand for each energy good as price elastic and responsive to policy and technology changes. The same applies to the energy demand of households. EMMA links emissions of $\mathrm{CO}_{2}, \mathrm{SO}_{2}$ and $\mathrm{NO}_{\mathrm{x}}$ to energy use. The connection between ADAM and EMMA is depicted in Figure 5. 


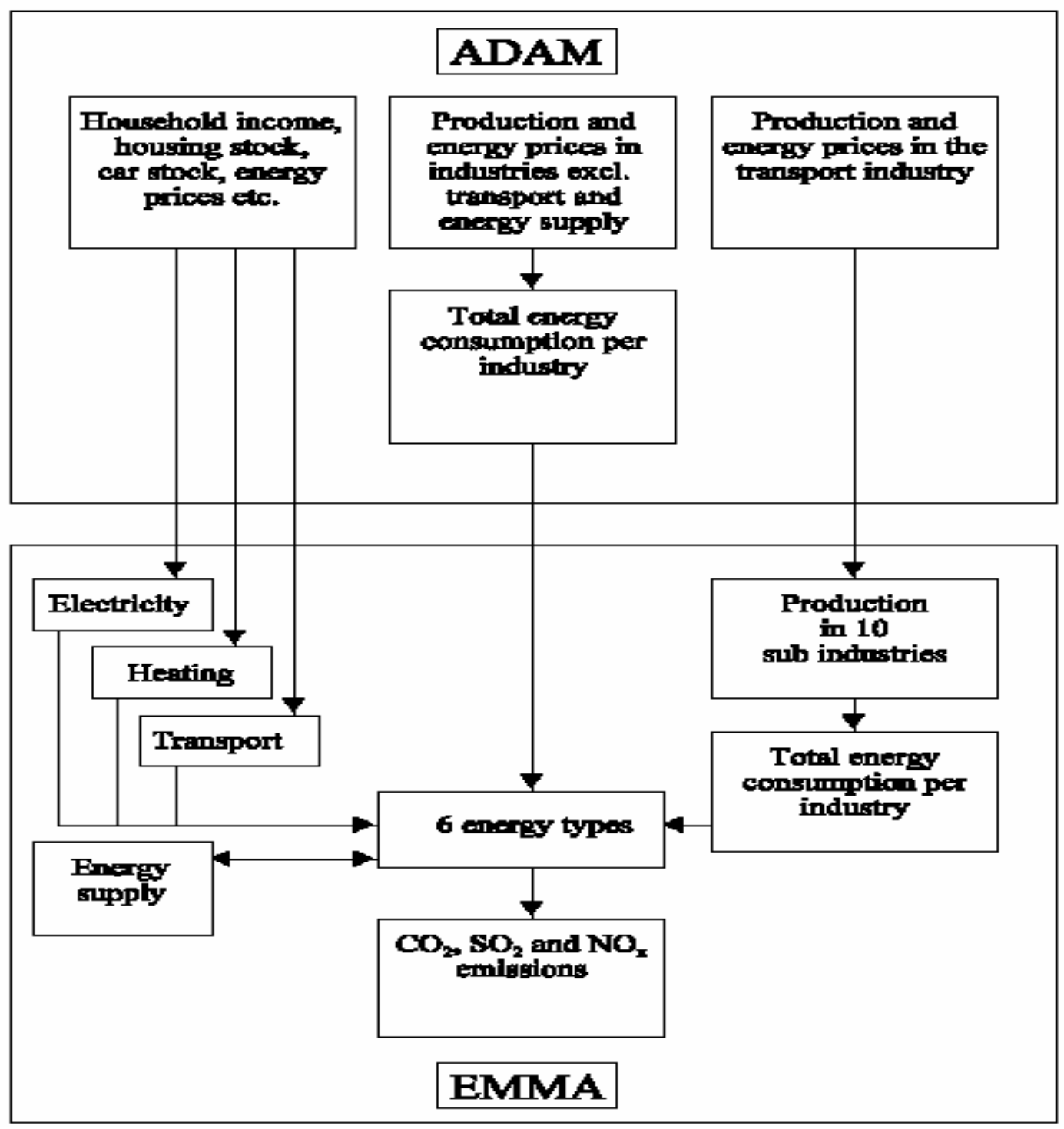

Figure 5: The connection between ADAM and EMMA

Source: Statistics Denmark (1996)

\subsubsection{Iceland}

Model and expertise: In the analysis of Iceland, we will use the Icelandic Viking model, developed by The Institute of Economic Studies (IoES) at University of Iceland. It is also a CGE model. So far the model has only been used in a static form. It has previously been used for, inter alia, analyses of abatement policy towards $\mathrm{CO}_{2}$. Our contact at IoES is Tryggvi Herbertsson. See Clements, Hall and Sturluson (1998) for a concise survey, Hall and Sturluson (2000) for a tax-policy application, and IoES (2003) for a climate policy application. 
Step

$-2$

Armington good

$\sigma_{\Lambda}=4$

1

-1 Export

Domestic produce

Imports

L

0

$$
\sigma \mathrm{x}=2
$$

Output

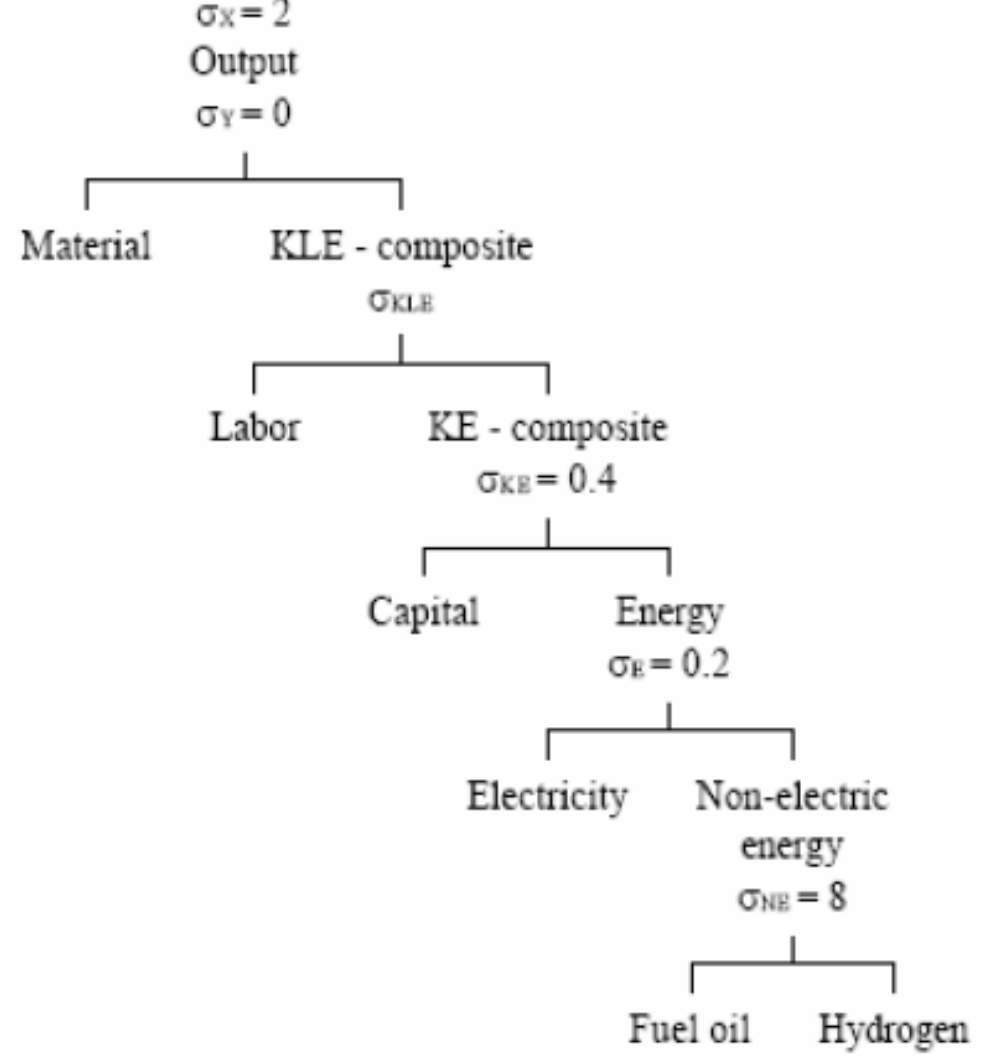

Figure 5: The Viking model's production structure

Source: Sturluson (2005)

Empirical and theoretical features: The Viking model is calibrated to a social accounting matrix of Iceland based on National Economic Institute's input-output accounts. In theoretical design it is fairly similar to the Swedish EMEC model. The production side is characterised by constantreturns-to-scale technologies and perfect competition in the goods markets. Production is defined by nested CES-functions; see Figure 5. Technological progress is exogenously driven, with one exception: A hydrogen sector, which is inactive under current circumstances is allowed to replace gasoline and diesel oil for private and public road transport if it becomes competitive under alternative relative prices. Contrary to the 
Swedish EMEC model and the Norwegian MSG6 model, the capital markets are not assumed to be completely open, and capital is sector-specific to a certain degree, depending on the time horizon.

The structure on the consumer side is described in Figure 6. There is a Cobb Douglas utility function, implying that there is substitutability among consumer goods, but with similar elasticity (=1). The labour supply is endogenous. The elasticity of substitution between leisure and consumption is chosen so that the uncompensated wage elasticity of labour supply is 0,1. See Clements, Hall, and Sturluson (1998) for details.

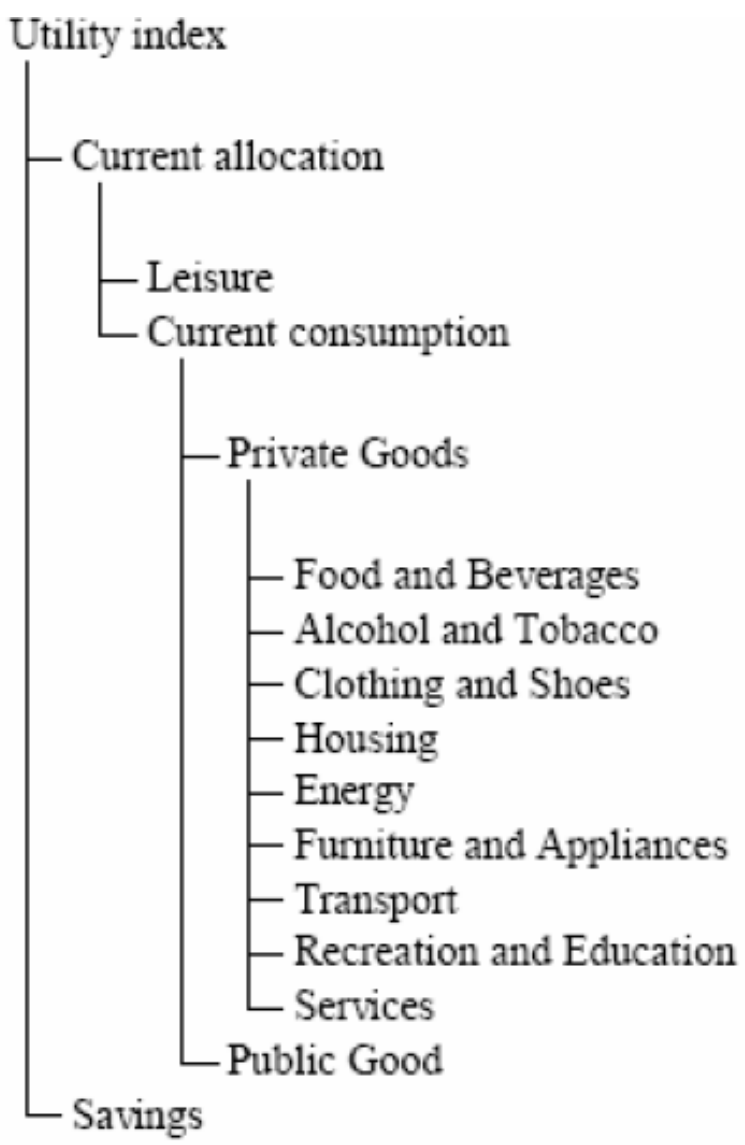

Figure 6: Household allocation structure of the Viking model

Source: Sturluson (2005)

Suitability for environmental decomposition analyses: The Viking model has a less disaggregated structure of industries and goods than the other models. It includes 20 sectors of production, thereof four energy sectors and four transportation sectors. These goods are mapped into 9 consumption goods. There is substitutability among inputs in the firms and among consumption goods in the households. $\mathrm{CO}_{2}$ emissions are linked to the use of fossil fuels or, in case of emissions from industrial processes, to output. Other environmental indicators have not yet been implemented. 


\subsubsection{Compatibility and comparability of the Nordic models}

All the models seem fit for decomposition purposes, in the sense that emissions depend on the composition of inputs in production, which is responsive to relative price changes of inputs, including policy-induced price changes and changes in emission coefficients (the environmental technology level). The composition of consumer goods is also sensitive to price changes, which give potentials for emissions to change endogenously to adjustments in relative consumer prices. In the Norwegian model, consumption goods, and thereby emissions, are also incomesensitive. The aggregation levels of the models vary somewhat, but they are all sufficiently disaggregated to produce interesting composition effects; cf. the description of the decomposition procedure in section 1.2. This also implies that substitution among inputs is specified at fairly disaggregate levels, which ensures interesting energy-intensity effects and material-intensity effects. The energy mix effect will also be possible to distinguish in all the models, as they specify at least two different energy inputs.

In all the models, environmental effects of economic activities are proxied by the emissions they cause. This means that the damage that emissions cause on materials, health, recreation etc. is not quantified, nor are the feedbacks on the economy in terms of lowered productivity, faster capital depreciation etc. All models include $\mathrm{CO}_{2}$ emissions. The models of Norway, Denmark and Sweden also include emissions of the acidifying emissions $\mathrm{SO}_{2}$ and $\mathrm{NO}_{\mathrm{x}}$. The Norwegian and Swedish models also include several other emissions.

The models have significant dissimilarities with respect to their economic features and theoretical foundation, which represent challenges for performing coordinated projections. The most deviating model is the Danish ADAM model, which is not a CGE model, as opposed to all the others. The bias of the CGE models is on long-run relationships in accordance with theories of economic behaviour. With our long-run perspective, the CGE models are suitable. The ADAM model, on the other hand, puts relatively more emphasis on tracking year-to-year changes by capturing short-run dynamics found in data. However, also in ADAM the long-term features are more in line with equilibrium theory and less affected by short-term dynamics. For long-run results, compatibility with the other models can therefore be satisfactorily ensured.

However, some important differences still remain. First of all, unemployment effects are, á priory, not only a short-run phenomenon in ADAM, as is implicitly presumed when unemployment is left out of CGE models. In simulations of different shocks given to ADAM, unemployment does nevertheless tend to regain its original level after about 10 years. Along with this, wages, and thus domestic prices, will in the long run stop adjusting and find their new levels. Though this will tend to happen slower than in CGE models, where wages (and prices) immediately 
adjust to obtain labour market equilibrium, the presence of unemployment in ADAM seems not to be a serious obstacle for comparability among the long-run projections of the models. To the extent that shorterterm results are of interest, it will also be possible to reconsider the most deviating parameters of the models, so that the mechanisms become more synchronised.

Several of the features of ADAM tend to make the description of the Danish economy less sensitive to world market conditions and foreign competition than what the CGE descriptions of the other Nordic countries do. The sluggishness of the wage rate is one reason for smaller effects on competitiveness in the shorter run. Further, the trade elasticities are smaller, implying that an effect on competitiveness is of less harm to domestic firms. The development of the trade balance is not necessarily in accordance with constraints that sooner or later will have to apply, in order to prevent an unsustainable balance of payment and continuously rising debt. However, in a comparison between the ADAM model and a Danish dynamic CGE model, DREAM (Pedersen and Rasmussen, 2000) the authors interestingly find that the long-term responses to shocks in the two models are qualitatively similar and of comparable magnitudes. ${ }^{2}$ This is more so when the parameters, for instance the trade elasticities, were adjusted to be in accordance with each other.

Also within the CGE models, the assumptions vary with respect to their dependence on world market conditions. In the Norwegian MSG6 model world market prices are fixed, and Norwegian firms act as price takers in the export markets. This avoids that there will be terms-of-trade effects of increasing domestic costs. In the other models, foreign demand for export products is downward-sloping, but with relatively high elasticities to avoid unrealistically strong terms-of-trade effects.

One of the conclusions in Pedersen and Rasmussen (2000) is that the deviating consumption modelling between DREAM and ADAM seemed to be of relatively little significance to the long-run results. This supports the hypothesis that the consumption behaviour in ADAM, which depends on current income and wealth, in many cases will resemble the intertemporal behaviour of rational, perfectly foresighted consumers as assumed in DREAM, as well as in the dynamic CGE models in this project.

A seemingly important difference between the Norwegian MSG6 model and the remaining models is the modelling of expectations. Agents in the Norwegian model are assumed to be perfectly rational and foresighted, having an infinite time horizon, while the other CGE models have adaptive agents. This is not a serious difference, after all, as the Norwegian model may be run with a closure rule that makes the expectations adaptive in line with the other models.

\footnotetext{
${ }^{2}$ Despite being a CGE model, DREAM accounts for unemployment and wage negotiations and is not qualitatively departing from the ADAM model in that respect.
} 
Another difference between the models concerns the labour supply modelling. In the Swedish model there are two types of labour. The endowments of each type are exogenous. In the Norwegian and Icelandic models there is one type of labour, and the supply is endogenously determined by the consumers' optimisation, given the wage rate, the prices of consumer goods, savings and income components. The Danish model has one labour type in endogenous supply, and qualitatively the same components play a role in its determination. The Norwegian model can easily be closed in another manner so that total labour supply is exogenous. This procedure can most probably be implemented in the Icelandic model, too.

The development of the technological level is exogenously determined in all the models. To ensure comparability, it is important to coordinate these assumptions. It is reasonable to assume that the small, open countries of Northern Europe share the same access to global technological breakthroughs. There is some endogeneity of technological change in the Norwegian and the Icelandic models. In MSG6 of Norway endogenous introduction of gas power is modelled, and in the Viking model of Iceland a similar modelling of hydrogen technology is included. Similar processes could be of potential interest to the other economies, and we can exploit the information from MSG6 and the Viking model also in the projections for the other economies. In addition to the exogenous and endogenous changes in production technologies, anticipated changes in emission coefficients will have to be exogenously accounted for and coordinated among the country projections. All of the models account for endogenous changes in production techniques, i.e. adjustments of input compositions depending on relative prices of inputs. Composition of inputs is an important determinant to emissions, as some inputs emit, some do not.

To conclude, there will be challenges in order to ensure sufficient comparability among the models. These challenges will be more serious, the less the model has been used previously for economic projections. The experience with the models for Norway, Denmark and Sweden is already solid. Their economic features and their sensitivity to various parameters and modelling designs are already well known. Many of the critical assumptions are modelled in a flexible way and can be easily adjusted. For instance, the ADAM model is already systematically compared with a Danish dynamic CGE model, and the short- and long-run implications of choosing the two different traditions are analysed and well understood. Another example is the experience with the use of the Norwegian model, which is frequently used for projections both with a fully dynamic, a semi-dynamic and a static determination. Simulations with both endogenous and exogenous labour supply are also performed. And procedures for adjusting the model in order to track short-run changes are also established. 
Besides adding difficulty, the differences among the models will, on the other hand, also add information. At fields where one model is particularly advanced, we can exploit the endogenous results for that country to make better exogenous estimates of the projections for the remaining economies. For example, information about technological changes in road traffic from the Icelandic model, which explicitly models transformation to hydrogen technology, can give information on future competitiveness and employment of hydrogen technology also for the other Nordic countries. Another example is that the models that incorporate endogenous labour supply can provide information relevant for the Swedish projections on deviations between its (exogenous) growth of labour supply and population growth.

\subsection{Practicability}

The main conclusion from the model survey above is that the four models picked out to be the most relevant in the respective countries, include all the data needed (cf. Table 1) to perform the decomposition in equation (2), both with respect to changes over time and between $\mathrm{CO}_{2}$ policy alternatives. We consider the designs of the models well suited for environmental decomposition analysis, as they are all sufficiently disaggregated wrt. environmentally harmful production processes, input, and consumption activities though at somewhat different levels of aggregation. These activities are all sensitive to price, scale, income, technology and policy changes, which is essential for identifying changes in the components determining emissions. $\mathrm{CO}_{2}$ emissions are modelled for all the countries, while the models for Norway, Sweden and Denmark also comprise the emission compounds $\mathrm{NO}_{\mathrm{X}}$ and $\mathrm{SO}_{2}$.

When comes to the comparability of the model simulations across countries, there are differences in theoretical foundations that affect the economic and, thus, the environmental outcomes. Though the empirical and theoretical features of the models seem reasonably well in accordance with evidence and economic theory, they vary somewhat with respect to their assumptions and approximations of economic realities. However, the challenges related to ensuring sufficient comparability among the models are not too serious. In many cases, outlaying features of a model can be approached to the others' by simple changes in the model formulations or parameters, and many of the institutions have experience for doing so. We thus conclude that there will be possible to compare the decomposed factors between countries and to ensure consistency in the exogenous, inter-country factors.

Running and analysing large-scale economic models requires modelspecific competence and experience. Coordination of the simulations is required along the project period. Coordination is first of all necessary 
concerning basic exogenous assumptions, such as international technological spillovers, prices on the international markets and international environmental agreements. To the limits of feasibility, it is desirable to do standardisations of the model specifications and simulations, in line with the discussion above. Another coordination challenge is the treatment of Nordic trade and the derivation of consistent common Nordic market conditions, relative competitiveness, and trade patterns. This will require simulation iterations among the models until their projections are consistent.

Because coordinating several models is necessary, and because high model expertise is necessary in order to run the models and interpret the results, this approach requires willingness and opportunity of researchers associated to the various national model institutions to participate actively in the project. Our mapping of the interest of Nordic model groups shows that there are competent senior researchers in all the four countries willing to take an active part in the project. A well-functioning network is necessary. There already exists a consortium of Nordic model institutions that the project can take advantage of, comprising most of the model institutions willing to participate in a forward-looking model project (Statistics Norway, National Institute for Economic Research in Sweden, and Statistics Denmark.)

\subsection{Policy relevance}

Model simulations from now throughout the next decades are suitable tools for projecting on future outcomes and thus what environmental challenges will be faced in the future. A main caveat of forward-looking simulations is their considerable uncertainty. Partly this is related to which economic and behavioural mechanisms are included in the models and how accurately they are quantified. In general, the selection of relations and their quantifications are based on backward-looking statistical analyses or present observations.

But even if the models to a reasonable degree capture how the economies have functioned until now, still it is uncertain whether some important economic mechanisms quantitatively or qualitatively will deviate in the future from their past and present performance. Inclusion of exogenous assumptions on such deviations is needed. An advantage of the forward-looking approach is that such assumptions about future changes will be integrated into the analytical framework. This will ensure a consistent treatment of future expectations. It is, however, important that the estimates of the model and their anticipated future changes are explicitly and transparently presented. Sensitivity simulations can be used to test the significance of selected assumptions considered to be particularly uncertain. This implies that the models are simulated with different assump- 
tions assigned to selected variables or relations to reveal their importance. In Bruvoll and Fæhn (2006) different climate policy assumptions are, for instance, compared to identify the sensitivity of the results to different future assumptions.

An advantage of using large-scale model simulations is the opportunity to isolate the contribution of single factors within each component described in section 1.2. The more detailed the decomposition, the more likely it is that the analysis reveals the relevant causal relationships that determine emissions. This will increase the relevance of the findings for practical policymaking, as we can identify where policy instruments should be implemented. It is relatively easy to lift a relevant factor in or out of the scenario in order to identify its isolated contribution. Examples could be the significance of specific technological developments, certain policy instruments, assumptions about the future resource situation, anticipated international trends etc. In Bruvoll, Fæhn and Strøm (2003) the isolated effect of an anticipated climate policy change is identified by this method.

A similar approach can also be used to identify the effects on emissions (and on growth) of different abatement policy efforts among the Nordic countries. Further, it can be used to identify effects of changing the policy assumptions, e.g. to compare policy scenarios where climate policy continues at present levels, where Kyoto commitments are taken into account, or where alternative national or Nordic initiatives are implemented.

While the policy questions discussed until now have relevance in single-country studies, as well as in a coordinated Nordic study, some additional questions can only be efficiently addressed in a coordinated, multicountry setting like in the Nordic project. This includes for instance the issue of transboundary environmental problems or the problem of global climate change. In addressing such issues, the national achievements are obviously misleading environmental indicators. An aggregate Nordic perspective is the more relevant. The Nordic perspective is also interesting for more local problems insofar as we are concerned with the distribution of environmental load among the countries. Both the efficiency and distribution aspects must be considered in evaluations of Nordic abatement policies, coordination efforts, and future agreements among the Nordic countries.

Even if we are only interested in national consequences of the country's own emissions, domestic emissions are interlinked with the economic development of other countries. Countries, and especially the small and open Nordic countries, are interlinked through their participation in international trade and investments and through reciprocal technological and political impulses and cooperation. This adds to the policy relevance of considering the Nordic countries in coherence. 


\subsection{Scientific value}

The forward-looking, large-scale model approach constitutes a novel method of analysing the driving forces of emissions in growing economies. It is yet only performed for one Nordic country, Norway, and within the MSG model. In Bruvoll, Fæhn and Strøm (2003), the hypotheses behind the Environmental Kuznets curve are simultaneously quantified within a consistent framework. In a related work, Bruvoll and Larsen (2004) decompose the changes in $\mathrm{CO}_{2}$ emissions caused by the $\mathrm{CO}_{2}$ taxes. These contributions are, to our knowledge, pioneers in the international literature. While previous empirical contributions based on largescale models have concentrated on contributions from single factors, like technological breakthroughs or political reforms, these studies take advantage of combining two methods, CGE simulations and a decomposition procedure, to single out the simultaneous contributions of scale, composition, technology and policy effects and their detailed components. Forward-looking analyses have previously been performed by extrapolating by aggregate, econometrically estimated models built up by one of a few relations (see e.g. Antweiler et al. (2001) for an excellent example). Such models are, however, far too simple and specify too few variables to make detailed predictions of causalities that can be useful for policy assessments.

A multi-country perspective adds insight compared to Bruvoll, Fæhn and Strøm (2003). Even though we expect some of the driving forces to be of general appliance to most Western countries, significant dissimilarities in the current and future industrial composition raise the need for country-specific analyses. The large petroleum sector in Norway, and its anticipated contraction in the future, dominates the environmental impact of future structural changes in Norway. Dissimilar compositions of electricity technologies among the Nordic countries now and in the future will also play an important role. The countries also differ with respect to the shares of primary, secondary and tertiary sectors, which potentially affect the extent of decoupling between growth in emissions and aggregate production.

A coordinated study has the advantage of eliminating or controlling undesired dissimilarities among the models and exogenous assumptions. Thus, the comparative study will seek to purify the country characteristics of interest and relevance. Some of the differences among the models even add information that can be exploited in the analysis. At fields where one model is particularly advanced, we can exploit the endogenous results for that country to make better exogenous estimates of the projections for the remaining economies.

Further, it is possible to incorporate a consistent picture of the development of Nordic trade into each of the country analyses. As pointed out above, the economic development of Nordic countries and their emis- 
sions are interrelated through their participation in the global markets, including direct trade with each other.There is significant trade among the Nordic countries. For Sweden, Denmark, and Norway, the other two countries rank among the 6 most important trading partners both in terms of imports and exports. (For Norway, this relates to export exclusive of oil and gas.) Trade with other Nordic countries constitutes between 20 and 30 per cent of the external trade of these countries. Important goods within these flows are electricity, food and beverages, transportation equipment (mainly from Sweden), electric equipment and machinery, metals and oil (mainly from Norway).

Changes in relative competitiveness among Nordic firms will change the intra-Nordic trade patterns, as well as their competitive positions and relative export activities in third countries. This will, again, be decisive to the allocation of emissions among the Nordic countries. Consequently, the market changes within the other Nordic countries feeds significantly back to the domestic environmental development of each country. In a study for Norway, we find that leakages of emissions abroad related to changes in trade constitute considerable amounts compared to domestic emissions, see Bruvoll and Fæhn (2006). It will be crucial to take such leakages among the Nordic countries into account, in order to have a consistent grip on emissions within each country. If model predictions for instance indicate that e.g. Denmark increases her export of electricity, it is essential to consider whether this should be mirrored in the import of electricity in other Nordic countries. There will be a need for coordinating the effects on intra-Nordic trade. The methodological challenges and solutions is another aspect of scientific interest with a forward-looking approach. 


\section{Conclusions and recommendations on the project design}

\subsection{Main conclusions on practicability}

Both the backward-looking and the forward-looking approach to decomposition of Nordic emissions are practicable. The analytical tools and data needed for such decompositions are available and well-established. They are suitable for the analysis, and they are reasonably compatible with each other. The expertise is high.

The backward-looking perspective demands least resources, as most data is readily available. In the Norwegian case, such an analysis for the period 1980-1996 is already performed. Hence, new analyses are most relevant for the other countries, unless analyses are to be made for the exact same time period for all countries. Data adjustments need to be done for the Icelandic and Norwegian data.

Coordination is less required in a backward-looking project. Some adjustments of the data and coordination between the statistical expertises in the Nordic countries are needed, but in general, the need for coordination along the project period seems manageable, given that a common decomposition procedure etc. is clarified.

The forward-looking perspective demands closer coordination, both with respect to exogenous inputs, steps to approach the model characteristics and iterations between the models to ensure that endogenous results are consistent among the models. This refers first of all to compatible representations of changes in Nordic market conditions, relative competitiveness, and trade patterns. Besides, active participation from the institutions in running the models and interpreting the results is a precondition. A well-functioning network is thus particularly necessary in a forwardlooking approach. All institutions are willing to participate actively in the project, and we can benefit from an already established model network.

\subsection{Main conclusions on policy relevance}

The forward-looking approach is most policy relevant, as it focuses on current and forthcoming environmental and climate challenges. In addition, the analytical tools for running alternative policy scenarios are available. 
A mapping of the past relationships between economic development and emissions can add insight into future environmental challenges. However, earlier studies indicate no constancy in driving forces over time, or between emission types. The relevance of backward-looking analyses for policy planning is only present when combined with expectations about future. This represents a challenge to the analyst in drawing policy-relevant conclusions, or to policy-makers in searching guidelines. It is difficult to do this in a consistent and coherent way without an analytical tool. The problem of an uncertain future is present in both approaches. Still, the model approach is designed for integrating knowledge about current and historical economic mechanisms with assumptions about future expectations. Using forecasting models thus avoids the uncertainty related to lack of consistency and coherence. The uncertainty about the future still remains. Models are useful for mapping the sensitivity of the results to different assumptions, thus getting insight into the degree of uncertainty.

It is not possible to identify causal relationships in a decomposition of historical emission changes (then econometric methods are needed). This further reduces the policy relevance of the results. In particular, it is not possible to isolate the impact of policy changes. A forward-looking model approach has a larger potential for isolating partial contributions from specific factors. It is easy to lift a relevant factor in or out of the scenario in order to identify its isolated contribution to the development of emissions, such as specific technological changes, special international events, or in particular, policy actions.

\subsection{Main conclusions on scientific value}

The tools we use for decomposing impacts of economic development on emissions are well established, in particular when comes to the historical decomposition methods. The methodological and empirical innovations of a Nordic project first of all relates to the establishment of a multicountry framework. The innovative spin-offs of a multi-country approach are most valuable in the forward-looking approach; for the backwardlooking perspective, the analyses in each country can in principle be done partially, and some are already available.

The challenges of coordinating several forward-looking model simulations require new methodological solutions. This applies to methods for standardising the model specifications and simulations. In particular, the need for coordinating endogenous results on Nordic market conditions, relative competitiveness, and trade patterns has a potential for inspiring methodological development. This process is likely to result in a tool for forecasting and analysing regional net emissions and the role of transboundary emissions and emission leakages. Additional spin-offs from this 
development could be improved insight into the existing country models and improved country models and analyses.

The empirical results from a Nordic study is also potentially of interest, as the decoupling hypothesis is not yet analysed for most of the Nordic countries. Using coordinated country study simulations will, in addition, provide insight to the phenomena of regional all-Nordic emission growth, transboundary emissions and emission leakages. As an all-Nordic macro-economic model is yet not developed, this insight is still lacking.

\subsection{Main recommendations}

In spite of its larger scale ${ }^{3}$, we recommend the forward-looking perspective due to its considerably higher policy relevance and scientific value:

Policy relevance:

- A forward-looking perspective provides results directly relevant to current and forthcoming environmental and climate challenges. It is difficult with high uncertainty to adjust historical results to future expectations without a consistent and coherent analytical tool. Model simulations constitute such a framework.

- A forward-looking model approach can reveal possible causal factors behind future emissions. In particular it can identify the quantitative effects on policy actions on emissions in total, and through each of the decomposed factors.

Scientific value:

- The method, involving to combine decomposition procedures with model projections, and to include individual macroeconomic models in a common framework, is more innovative than pure decompositions of each country's statistical data.

- A forward-looking perspective is most likely to contribute to new knowledge on the decoupling hypothesis. Several backward-looking decomposition analyses have already been performed for three of the countries. Compared to individual country studies, a coordinated approach provides insight into net growth in the region, to transboundary emissions and to emission leakages.

- This method requires strong coordination of several international models and modelling institutions. This will benefit the quality of each country's analytical tools and serve to establish a valuable Nordic research network.

\footnotetext{
${ }^{3}$ When comes to an estimated budget for a forward-looking project, we refer to the tentative project description attached to the application for the pre-study dated November 16., 2005.
} 



\section{References}

Aasness, J \& B. Holtmark (1995): Effects on Consumer Demand Patterns of Falling Prices in Telecommunication, Working Paper 1995:8, Centre for International Climate and Environmental Research - Oslo (CICERO).

Andersen, F.M., H. K. Jacobsen, P. E. Morthorst, A. Olsen, M. Rasmussen, T. Thomsen \& P. Trier (1997): Energi- og emissionsmodeller til ADAM, Danmarks Statistik.

Antweiler, W, B. R. Copeland \& M. S. Taylor (2001): Is Free Trade Good for the Environment? The American Economic Review, September, $877-908$.

Bruvoll, A. \& T. Fæhn (2004): Transboundary environmental policy effects: markets and emission leakages, Discussion papers 384, Statistics Norway, forthcoming in Ecological Economics.

Bruvoll, A. \& T. Fæhn (2006): Richer and cleaner - at others' expense?, forthcoming as Discussion Paper, Statistics Norway.

Bruvoll, A., T. Fæhn, \& B. Strøm (2003): Quantifying central hypotheses on environmental Kuznets curves for a rich economy: A computable general equilibrium study. The Scottish Journal of Political Economy, 50(2): 149-173.

Bruvoll, A., K. Flugsrud \& H. Medin (2000): Dekomponering av endringer i utslipp til luft i Norge - dokumentasjon av data. (Factoring the changes in emissions to air in Norway - documentation of data), Notater 2000/68, Statistics Norway.

Bruvoll, A. \& B. M. Larsen (2004): Greenhouse gas emissions in Norway. Do carbon taxes work? Energy Policy 32 (4), 493-505.

Bruvoll, A. \& H. Medin (2003): Factors behind the environmental Kuznets curve, evidence from Norway. Environmental and Resource Economics, 24(1): 27-48.
Bye, B. (2000): Environmental tax reform and producer foresight: An intertemporal computable general equilibrium analysis, Journal of Policy Modeling 22(6), 719-752.

Bye, B. (2002): Taxation, unemployment and growth: Dynamic welfare effects of "green" policies, Journal of Environmental Economics and Management 43, 1-19.

Bye, B. \& K. Nyborg (2003): Are Differentiated Carbon Taxes Inefficient: A General Equilibrium Analysis, The Energy Journal 24(2), 1-18.

Clements, L. A., A. Hall \& J. T. Sturluson (1998): The Viking CGE Model: A Concise Survey. Institute of Economic Studies Working Paper Series, University of Iceland.

Dinda, S. (2004): Environmental Kuznets curve hypothesis: A survey, Ecological Economics 49, 431-455.

Fæhn, T. \& E. Holmøy (2003): Trade Liberalisation and Effects on Pollutive Emissions and Waste: A General Equilibrium Assessment for Norway, Economic Modelling 20(4), 703-727.

Hall, A. \& J. T. Sturluson (2000), “Testing a CGE Model: The Tax-Free Year in Iceland as a Natural Experiment”, in ed. Gudmundsson et al. Macroeconomic Policy: Iceland in an Era of Global Integration. University of Iceland Press.

IoES (2003), "The Economic Impact of Kyoto”, Institute of Economic Studies Working Paper Series, University of Iceland.

Heide, Kim Massey, Erling Holmøy, Lisbeth Lerskau and Ingeborg Foldøy Solli (2004): Macroeconomic Properties of the Norwegian Applied General Equilibrium Model MSG6, Reports 2004/18, Statistics Norway.

Jensen, P. R. \& T. Olsen (2003): Analysis of changes in air emissions in Denmark 1980-2001, Statistics Denmark.

Nilsson, C. (2004) "Household Transport Demand in a CGE-framework" in Studies in Environmental Econom- 
ics: Numerical Analysis of Greenhouse Gas Policies, Dissertation, Stockholm School of Economics, Stockholm.

Nilsson, C. \& A. Huhtala (2000) "Is CO2 Trading Always Beneficial?” A CGE-Model Analysis on Secondary Environmental Benefits, Working Paper no. 75. National Institute of Economic Research.

Pedersen. L. H. \& M. Rasmussen (2000): Langsigtsmultiplikatorer i ADAM og DREAM - en sammenlignende analyse, Economic Working Paper Series 2000/1, Statistics Denmark.

Selden, T. M., A. S. Forrest \& J. E. Lockhart (1999): Analyzing the reductions in US air pollution emissions: 1970 to 1990, Land Economics 75 (1), 1-21.

SOU 2000:7, Långtidsutredningen 1999/2000.

SOU 2000:23, Förslag till svensk klimatstrategi - Klimatkommitténs betänkande.

SOU 2000: 45, Handla för att uppnå klimatmål! - Kostnadseffektiva lösningar med flexibla mekanismer inom klimatområdet.

SOU 2001:2, Effektiv hushållning med naturresurser.

SOU 2003:60, Handla för bättre klimat.

SOU 2004:19, Långtidsutredningen 2003/04.

SOU 2005:10, Handla för bättre klimat - Från införande till utförande.

Statistics Denmark (1996): ADAM - en modell af dansk økonomi, at www.dst.dk/ADAM

Steigum, E. (1993): Accounting for long run effects of fiscal policy by means of computable overlapping generations models. In: S. Honkopohja and M. Ingeberg (Editors), Macroeconomic Modeling and Policy Implications. Elsevier Science Publishers B.V., Amsterdam, pp. 45-67.

Strøm, B. (2000): MSG-6: utslippsmodellenes ligningsstruktur: teknisk dokumentasjon, Notater 2000/22, Statistisk sentralbyrå.

Strøm, B. (2001): Velferdseffekter og samfunnsøkonomiske kostnader ved Norges oppfølging av Kyotoprotokollen, beregninger basert på en disaggregert, intertemporal, generell likevektsmodell, Hovedoppgave, Økonomisk institutt, Universitetet i Oslo. Sturluson (2005): Comparison of five Nordic Macroeconomic models with Structural Environmental Links, Decoupling Project - Phase 2, Memeo, Institute of Economic Studies, University of Iceland.

Wadeskog, A.\& V. Palm (2003): Structural decomposition of environmental accounts data - the Swedish case, Statistics Sweden.

Wier, M. \& B. Hasler (1999): Accounting for nitrogen in Denmark - a structural decomposition analysis, Ecological Economics 30; 317-331.

Wold, I (1998): Modellering av husholdningenes transportkonsum for en analyse av grønne skatter: $\mathrm{Mu}$ ligheter og problemer innenfor rammen av en nyttetremodell, Notater 98/98, Statistics Norway

Östblom, G., (1999), An Environmental Medium Term Economic Model EMEC, Working Paper No. 69, Swedish National Institute of Economic Research, Stockholm.

Östblom, G., (2003) "Vinner Sverige på att delta i utsläppshandel?”, Ekonomisk Debatt, årg 31, nr 8, (in Swedish)

Östblom, G., \& Berg, C, (2006), Modelling Transport Demand in EMEC The EMEC Model:Version 2.0, Working Paper (Forthcoming) Swedish National Institute of Economic Research, Stockholm.

Östblom, G \& Samakovlis, E, (2004), Costs of Climate Policy when Pollution Affects Health and Labour Productivity - A General Equilibrium Analysis Applied to Sweden, Working Paper No. 93, Swedish National Institute of Economic Research, Stockholm. 